\title{
Selecting the most suitable classification algorithm for supporting assistive technology adoption for people with dementia: A multicriteria framework
}

Ortiz-Barrios, M., Nugent, CD., Cleland, I., Donnelly, MP., \& Verikas, A. (2020). Selecting the most suitable classification algorithm for supporting assistive technology adoption for people with dementia: A multicriteria framework. Journal of Multi-Criteria Decision Analysis, 27(1-2), 20-38. https://doi.org/10.1002/mcda.1678

Link to publication record in Ulster University Research Portal

Published in:

Journal of Multi-Criteria Decision Analysis

Publication Status:

Published (in print/issue): 02/03/2020

DOI:

10.1002/mcda.1678

Document Version

Author Accepted version

\section{General rights}

Copyright for the publications made accessible via Ulster University's Research Portal is retained by the author(s) and / or other copyright owners and it is a condition of accessing these publications that users recognise and abide by the legal requirements associated with these rights.

\section{Take down policy}

The Research Portal is Ulster University's institutional repository that provides access to Ulster's research outputs. Every effort has been made to ensure that content in the Research Portal does not infringe any person's rights, or applicable UK laws. If you discover content in the Research Portal that you believe breaches copyright or violates any law, please contact pure-support@ulster.ac.uk. 


\section{Selecting the Most Suitable Classification Algorithm for Supporting Assistive Technology Adoption for people with Dementia: A Multicriteria Framework}

\begin{tabular}{|r|l|}
\hline Journal: & Journal of Multi-Criteria Decision Analysis \\
\hline Manuscript ID & MCDA-19-0004.R1 \\
\hline Wiley - Manuscript type: & Research Article \\
\hline Date Submitted by the & Author: \\
\hline Complete List of Authors: & $\begin{array}{l}\text { Ortiz, Miguel; Corporacion Universitaria de la Costa, Industrial } \\
\text { Engineering } \\
\text { Nugent, Chris; University of Ulster School of Computing and } \\
\text { Mathematics, School of Computing } \\
\text { Cleland, Ian; University of Ulster School of Computing and Mathematics } \\
\text { Donnelly, Mark; University of Ulster School of Computing and } \\
\text { Mathematics } \\
\text { Verikas, Antanas; Hogskolan i Halmstad }\end{array}$ \\
\hline Keyword: & TOPSIS, FAHP, Assistive technology, Dementia, Classifier \\
\hline &
\end{tabular}

\section{SCHOLARONE Manuscripts}




\title{
Revised Manuscript-Marked
}

\section{Selecting the Most Suitable Classification Algorithm for Supporting Assistive Technology Adoption for people with Dementia: A Multicriteria Framework}

\author{
Miguel Ortiz-Barrios* \\ Department of Industrial Management, Agroindustry and Operations, Universidad de la \\ Costa CUC, 58 ${ }^{\text {th }}$ street \# 55-66, Barranquilla, Colombia, Tel: +573007239699 , \\ mortiz1@cuc.edu.co
}

\author{
Chris Nugent \\ School of Computing \\ Ulster University, Jordanstown, Northern Ireland, UK \\ cd.nugent@ulster.ac.uk \\ Ian Cleland \\ School of Computing \\ Ulster University, Jordanstown, Northern Ireland, UK \\ i.cleland@ulster.ac.uk \\ Mark Donnelly \\ School of Computing \\ Ulster University, Jordanstown, Northern Ireland, UK \\ mp.donelly@ulster.ac.uk
}

Antana Verikas

Center for Applied Systems Intelligent Research

Halmstad University, Halmstad, Sweden

antanas.verikas@,hh.se

*Corresponding author

\begin{abstract}
The number of people with dementia (PwD) is increasing dramatically in both developed and developing countries. PwD exhibit impairments of reasoning, memory and thought that fypically require some form of self-management intervention to support the completion of everyday activities while maintaining a level of independence. To address this need, efforts have been directed to the development of assistive technology solutions, which may provide an opportunity to alleviate the burden faced by the PwD and their carers. However Nevertheless, uptake of such solutions has been limited. it It is therefore necessary to use classifiers to diseriminating discriminate between adopters and non-adopters of these technologies in order to avoid cost overruns and potential negative effects on quality of life. As multiple classification algorithms have been developed, choosing the most suitable
\end{abstract}


classifier has become a critical step in technology adoption. To select the most appropriate classifier, For a proper selection, a set of criteria from different various domains need to be taken into account by decision makers. In addition, it is crucial to define the most appropriate multicriteria decision-making approach for the modelling of technology adoption. Considering the above-mentioned aspects, this paper presents the integration of a 5-phase methodology based on the Fuzzy Analytic Hierarchy Process (FAHP) and the Technique for Order of Preference by Similarity to Ideal Solution (TOPSIS) methods to determine the most suitable classifier for supporting assistive technology adoption studies. FAHP is used to determine the relative weights of criteria and sub-criteria under uncertainty and TOPSIS is applied to rank the classifier alternatives. A case study considering a mobile-based selfmanagement and reminding solution for persons suffering from dementia pwd is described to validate the proposed approach. The results revealed that the best classifier was k-nearestneighbour with a closeness coefficient of 0.804 and the most important criterion when selecting classifiers is scalability. The paper also discusses the strengths and weaknesses of each algorithm that should be addressed in future research.

Keywords: TOPSIS, FAHP, assistive technology, dementia, classifier.

\section{Introduction}

As a society, we are currently witnessing population growth and increased life expectancy on a global scale. This can be largely attributed to advances in the economy, healthcare provision, science and technology. With this comes a number of knock-on effects from a healthcare perspective, specifically evidenced through increased prevalence of persons suffering from long term chronic conditions. One such long term condition is that of dementia. Figures have estimated that the number of people suffering from dementia is expected to double every 20 years. Significant efforts have been directed towards the development of a pharmacological solution to prevent dementia, however, to date such a solution has not been produced identified. In the interim, efforts have been directed towards the development of assistive solutions for both people with dementia (PwD) and their careers.

Technology-based solutions to provide assistance to careers and to support PwD people with dementia have had increased levels of success in recent years. As technology becomes more pervasive, costs decrease, and battery life increases we should expect further instances of their usage. Although their prevalence has increased, to a certain extent their level of acceptance and perception of utility as an assistive solution for PwD persons with dementia has caused much debate. The lack of ability of technology-based solutions to offer a truly personalised experience as an assistive solution, fully embracing the intricate requirements 
of PwD people with dementia can be viewed as the challenges still to be addressed within the research and development community. As a result, there is now scepticism amongst healthcare professionals whether such technology-based solutions should actually be deployed. On the one hand, the deployment of a technology solution may have a negative effect, thereby causing it to be never used again ${ }_{\overline{5}}$. As a result, the PwD may never use, or any other technology-based solution to be used in the future. On the other hand, not offering a technology solution may exclude a person from having the opportunity to experience a form of assistance from which they may gain benefit.

To identify if a person will or will not adopt a new solution has led to adoption modelling studies. Here a range of parameters has been used to model the characteristics of both adopters and non-adopters and based on the input provided to the model a recommendation can be made whether or not to the user is likely to adopt use the solution. From a dementia perspective, adoption models, also called classifiers, have been used at the point of prescribing technology-based assistive solutions, to recommend if the persen with dementia PwD, based on their profile, will or will not have a positive experience in using the solution. To date, the development of adoption models has been addressed from a computational perspective where efforts have been directed towards identifying the best set of features to be used with an optimised classification model to produce the highest levels of classification performance. Such an approach, however, neglects to consider the different conflicting criteria representing the context within which the adoption model is being used, i.e., who, from a healthcare perspective is entering data into the model and who is reading its output, as well as the important performance metrics from a computational and classification perspective. It is then therefore necessary to find an approach that deals with the presence of multiple conflicting criteria and several classifier alternatives as those identified in the context of technology usage. In reply, the use of Multicriteria Decision Making (MCDM) methods can be considered for addressing this challenge. In fact, the main strength of MCDM methods is their ability to consider several criteria simultaneously and assess different options under variable degrees (Wang \& Pang, 2011). Therefore, MCDM methods seem to be the appropriate tool for helping developers, healthcare professionals and practitioners to select the most suitable classifier for supporting technology adoption for PwD. The next step is then to find a suitable MCDM approach for this particular aim. Such an approach must be coherent with the decision-making context of technology usage characterized by i) assignment of relative weights to criteria and sub-criteria, ii) uncertainty of input data and iii) integration of subjective and objective measures. The combination of two well-known methods are proposed for this particular aim: 1) Fuzzy Analytic Hierarchy Process (FAHP), a technique for calculating the relative weights of decision elements under uncertainty and vagueness (Izquierdo et al., 2016); 2) Technique for Order of Preference by Similarity to Ideal Solution (TOPSIS), a method that ranks the alternatives based on their separation to 
ideal and anti-ideal performance (Sengül et al., 2015). In addition, the use of hybrid methods has gained prominence due to their capability of addressing the limitation of single methods and offering more robust results (Zavadskas et al., 2016; Ortiz-Barrios et al., 2017).

The aforementioned methods support the deployment of an innovative 5 phase methodology, proposed in this paper, to determine the most suitable classifier for supporting assistive technology adoption studies. This approach is validated on a case study considering a mobilebased self-management and reminding solution for PwD persons suffering from dementia. The results from the study have demonstrated for the first time the benefits of considering a larger body of evidence in the design of adoption models and how such an approach can be generalised to other adoption scenarios. In addition, the application of MCDM methods for modelling the technology adoption is a novel contribution to the literature considering that previous studies have only evidenced one-size-fits-all approaches based on classification performance.

The following Section provides an overview of the area of adoption modelling with examples of how such models have been developed for assistive technologies. Furthermore, it provides a literature review on MCDM techniques that can be adapted to the context of technology adoption. Section 3 provides the details of the innovative 5 phase methodology while Section 4 provides details of the methodology being used with a Case Study in reminding technologies and discusses the findings. Finally, overall conclusions are presented in Section 6.

\section{Primary studies from the literature}

The following sections provide a detailed review of the literature with a particular focus on modelling adoption and selecting appropriate MCDM methods.

\subsection{Modelling adoption of assistive technology}

Modelling of technology adoption, using statistical and machine learning approaches is seen as a useful process in gaining an understanding of the factors influencing technology adoption (Chaurasia et al., 2016; Robillard et al., 2018). The aim of adoption modelling is to predict, from a set of features extracted about the individual and their environment, whether a technology will or will not be adopted by a user in the future. Such models can be used as screening tools for those who will or will not be able to use the technological solution. Additionally, adoption modelling has been used to predict the needs of the user, prior to offering the solution with the aim of improving applicability and acceptance of assistive technologies (Czarnuch et al., 2016). 
Over the past 20 years, a small number of attempts research studies have been made to develop measures for predicting technology adoption. Generally, it is considered that the adopter of a technology will be the individual who can use the technology and appreciates the utility of doing so. The original technology adoption model (TAM) focused on the concepts of perceived usefulness and ease of use (Venkatesh \& Davis, 2000). The strength of their model lies in its simplicity, with only these two constructs (Sharma \& Mishra, 2014). TAM was initially tested in the context of user adoption of email and file editor services, at IBM. It is, however, becoming increasingly evident that the likelihood of adoption is much more complex and multifaceted in nature than as described by this simple two-factor model. With increased diversity in the available technology, context, and users' background, it may be relevant to understand other factors that may affect adoption (Robillard et al., 2018).

TAM has been extended to include additional key determinants of perceived usefulness and usage intention (Venkatesh \& Davis, 2000). The additional constructs included social influence (subjective norm, voluntariness, and perceived image) and cognitive instrumental processes (job relevance, results demonstrability and quality). A more general approach is to separate these factors into external constructs such as social structures, regulatory environment and infrastructure, and personal factors such as perceived usefulness, selfesteem and expectations (Day, 1996). The Psychosocial Impact of Assistive Devices Scale (PIADS), which is an extension of TAM focuses on personal factors and acknowledges the existence of external factors such as people and society that may have an impact on usage and self-image. PIADS has been used implemented when considering adoption of assistive technologies (Day, 1996).

Whilst both TAM and PIADS have been popular constructs, they have been criticised due to their questionable heuristic value and lack of explanatory power (Chuttur, 2009). As a result of a systematic review of eight earlier models, Venkatesh et al., (2011) proposed the unified theory of acceptance and use of technology (UTAUT). It is meant designed to serve as a comprehensive model that can be applied across a range of applications. UTAUT combines four constructs of performance expectancy, effort expectancy, social influence and facilitating conditions. The UTAUT model provides a broader definition to the perceived usefulness of the technology. Additional factors incorporated within the model includes the social influence and facilitating conditions. It was found that gender, age, experience and voluntariness of use were the main moderating influences whereas self-efficacy, attitude, and anxiety did not have a direct influence on adoption. The unified theory is proposed to be superior as it is able to explain $70 \%$ of the variance while the earlier theories were explaining only 30-40\% variance in the adoption behaviour (Venkatesh et al., 2003). It is criticized however for being overly complex (Sharma and Mishra, 2014). Another model built by integrating TAM with mediating factors from UTAUT is the Mobile Phone Technology 
Adoption Model (MOPTAM). MOPTAM was used to model personal mobile phone use by university students (Phan \& Daim, 2011).

More recently, some studies have examined how different age groups may think differently and make different decisions around technology adoption (Guan et al., 2017). With the increasing research and societal interest in understanding factors that determine adoption in older patients, it is necessary to have a deeper insight into technology adoption through further research. This is evidenced by the evaluations of the Whole Systems Demonstrator (Shore et al., 2018). The demonstrator aims to build upon the existing qualitative evaluation in order to identify predictors of early removal of telehealth. For predicting mobile phone adoption by the elderly, a Senior Technology Acceptance \& Adoption model for Mobile technology (STAM) was described in Spreicer (2011).

Domain-specific models for prediction have also been proposed. Chaurasia et al., (2016) present TAUT (Technology Adoption and Usage Tool) that focuses on modelling adoption of assistive technology by people with dementia and their carers. The model was built upon a diverse dataset obtained by recruiting 335 participants from the Cache County Study on Memory in Aging (CCSMA) and linking this database to the Utah Population Database (UPDB). The database contained a mix of genealogical, medical, and demographic records, which was then categorized into 4 groups: 3 types of non-adopter ( 1 - willing but unable, 2 not willing and not able, 3 - not willing but able) and 1 adopter group. Non-adopters (willing but unable) were profiled along with the adopter's group. The study assessed the ability to classify whether an individual would agree or refuse to participate in this research study using a variety of data mining algorithms. The study also investigated the effect of feature selection on each algorithm, with Information Gain (IG) being employed to rank features in terms of discriminating power for classifications.

It is clear that adoption models have evolved immensely since first developed. They have now been extended to include a diverse range of constructs, user demographics, technical solutions, and use contexts. This will ultimately allow them to cope with the increasingly pervasive nature of technology. Indeed, the likelihood of adoption spans not only the physical design of the product and individual characteristics of the person, but also includes social settings and the pathways through which the technology is delivered and communicated. Moreover, user's perceptions of usability and usefulness may change over time as the perceptions, needs, and capabilities of the individual change, and the technology advances.

Lee \& Coughlin (2015) identified 10 factors as facilitators and/or determinants of adoption of technology. These factors included usefulness, usability, affordability, accessibility, technical support, social support, emotion, independence, experience, and confidence. When considering the adoption and continued use of assistive technologies this multifaceted view 
of adoption has been supported (Cook et al., 2016). When modelling the decision of older adults to use assistive technologies, for example, four themes where identified: acceptance of old age/health condition; previous knowledge and awareness of the equipment available'; 'perceived usefulness of equipment'; and 'attitudes and perceptions towards assistive technology'. Considering the continued engagement and usage of assistive technologies four related themes were identified; 'usability', 'usefulness of equipment', 'functionality of equipment' and 'threat to identity and independence'.

Existing evidence suggests important benefits for this approach (Zhang et al., 2014). Relatively simple regression-based models have demonstrated the ability to identify, with high levels of precision, individuals who are likely to wish to adopt technology-based solutions (Chaurasia et al., 2016). Input parameters to these models have ranged from details relating to education, living arrangements, prior technology experience and medical history (Chaurasia et al., 2016). Refinement of the adoption model has been possible through the inclusion of additional processing steps of selecting features which have aided in improving the generalization of the modelling process (Chaurasia et al., 2016). Data obtained from these models have allowed the characterization of end-users who are less likely to adopt a technology, thereby informing targeted efforts to reach these specific end-users and promote inclusivity in technology adoption. Although adoption modelling to date has been largely data-driven, there would be additional benefit in paying closer attention to the features selected as a result of computational techniques in an effort to understand their correlation with the notion of adoption. This additional knowledge driven perspective has the potential to assist with the overarching aim of making models transferable to different users and to different technology-based domains. Despite the multiple attempts that have been made to model the technology adoption, no studies using MCDM methods were detected. The next step is then to identify the most suitable MCDM approach to address this particular aim (see the coming subsection).

\subsection{Selecting the most suitable MCDM approach for the modelling of technology adoption}

In the reported literature, several single MCDM methods (e.g. Analytic Hierarchy Process (AHP), Analytic Network Process (ANP), Decision Making Trial and Evaluation Laboratory (DEMATEL), Technique for Order of Preference by Similarity to Ideal Solution (TOPSIS), Simple Additive Weighting (SAW) and Data Envelopment Analysis (DEA)) have been used by researchers and practitioners to address complex real-life problems with a multiple criteria nature. However, such Such methods, however, hold certain limitations in their structures. For instance, several studies have debated about the rank reversal problem presented in AHP, 
a phenomenon consisting of changes observed in the final ranking order after the addition or removal of an alternative (Ishizaka \& Labib, 2009; Rodriguez, Ortega and Concepción, 2016; Aires \& Ferreira, 2018). This problem is also a limitation in DEA (Soltanifar \& Shahghobadi, 2014; Shin, 2017) and SAW (Shin et al., 2013; Bendaoud, Didi \& Abdennebi, 2017; Aires $\&$ Ferreira, 2018). Another constraint in the DEA method is that positive outputs and inputs are needed for each decision-making unit - (DMU) (Huang \& Li, 2013). On the other hand, PROMETHEE (Preference Ranking Organization Method for Enrichment Evaluations) and TOPSIS do not evidence a mathematical-based procedure to determine the relative weights of criteria and sub-criteria (Behzadian et al., 2012; Velasquez \& Hester, 2013). Thus, some bias may be introduced when ranking the alternatives. In relation to ANP, the main drawback lies on the rigorous calculations that have to be undertaken for performing sensitivity analysis. This represents a barrier to its implementation in practical scenarios where decision makers are usually unskilled in complex mathematics and MCDM methods (Kumar \& Haleen, 2015).

Being aware of the aforementioned limitations, hybrid methods - approaches combining two or more single methods - are proposed to provide more robust and reliable outcomes while tackling the shortcomings of each MCDM technique (Zavadskas et al., 2016; Barrios et al., 2016). Their use has gained prominence in recent years in many complex and realistic scenarios. This is also due to the fact that hybrid approaches allow practitioners to integrate subjective and objective measures which is consistent with the decision-making context of technology usage. However, as As numerous MCDM techniques exist, however, selecting the most suitable MCDM hybrid approach is pivotal in technology adoption modelling. Such a problem involves allocating the final weights of criteria and sub-criteria in the final decision. In this regard, the Fuzzy MCDM (FMCDM) approaches are lately capturing increasing attention lately due to their capability of assessing the priorities of decision elements while considering the vagueness and ambiguity of human judgments (Shaverdi et al., 2014; Ishizaka, 2014; Mardani et al., 2015). For example, Cho \& Lee (2013) implemented FAHP to prioritize factors in a new technology product assessment model, while Shieh et al. (2013) developed it to analyse the importance of several factors in the adoption of mobile services in Taiwan. Mainly, in these studies, FAHP has been used for evaluating the criteria weights under uncertainty while another approach that uses those weights is applied to ranking the alternatives. For instance, Lin (2017) combined the FAHP approach with VIKOR to find optimal solutions for mobile technology adoption in travel agencies. Additionally, Yadegaridehkordi et al. (2018) integrated FAHP and structural equation modelling approaches for predicting the adoption of cloud-based technology in the educational context. Nevertheless, FAHP has not been adopted together with TOPSIS for supporting technology adoption. In particular, TOPSIS can be used for selecting the best option from a predefined set of alternatives (Sengül et al., 2015; Chen, 2015) as required in 


\section{Methods}

\subsection{The Proposed Methodology}

A five-phase methodology (Fig. 1) was is proposed to determine the most suitable classifier for supporting assistive technology adoption:. This is described as follows:

Phase 1: A decision-making team is chosen based on their experience for solving the problem. The experts will be invited to be part of the decision-making process through Fuzzy Analytical Hierarchy Process (FAHP) technique.

Phase 2: The criteria and sub-criteria are established through consideration and combination of the pertinent literature and expert opinion.

Phase 3: FAHP is used to estimate the relative importance of criteria and sub-criteria under uncertainty. In this phase, the experts were invited to perform pairwise judgments which are subsequently processed in accordance with the FAHP method, as detailed in Section 3.2.

Phase 4: The Technique for Order Preference by Similarity of an Ideal Solution (TOPSIS) method was implemented to rank identified classifiers from highest to lowest based upon their closeness coefficient (described in Section 3.5).

Phase 5: The best classifier is selected (the alternative option with the higher closeness coefficient) to support the assistive technology adoption decision task.

Figure 1: The five-phase methodology for selecting the most suitable classifier for supporting assistive technology adoption in people with dementia.

\subsection{The Fuzzy Analytic Hierarchy Process (FAHP)}


The Analytic Hierarchy Process (AHP) has been widely applied in different studies for addressing MCDM problems in practical scenarios (Saaty \& Vargas, 2012; Saaty, 2013; Ortiz-Barrios et al., 2017). However, AHP, however, is unable to represent the inherent uncertainty and vagueness that decision makers experience when comparing the relative importance of one criterion/sub-criterion in terms of another (Ertuğrul \& Karakaşoğlu, 2009). To overcome this barrier, Fuzzy AHP (FAHP) is introduced based on the fact that fuzzy numbers can effectively express the imprecise comparisons ratios (Izquierdo et al., 2016). Thereby, the decision-making accuracy can be increased when tackling real-world problems. Furthermore, decision makers are empowered to feel more confident to provide interval judgments rather than being constrained to provide crisp values. In addition, non-obtainable and incomplete information can be incorporated in the MCDM model using FAHP (Dağdeviren, \& Yüksel, 2008). The uncertain judgments are expressed through triangular fuzzy numbers $M$ which are denoted by three real numbers $(a, b, c)$. In a triangular fuzzy number, $a$ and $c$ represent the lower and upper limit respectively while $\mathrm{b}$ denotes the mean. The membership function for $\tilde{M}$ is described as follows:

$$
\mu_{M}(x)=\left\{\begin{array}{ll}
\frac{x-a}{b-a}, & a \leq x \leq b \\
\frac{c-x}{c-b}, & b \leq x \leq c \\
0, & \text { otherwise }
\end{array} \quad \text { Here, }-\infty<a \leq b \leq c<\infty .\right.
$$

The fuzzy scale proposed for making the pairwise uncertain judgments are presented in Table 1. A reduced version of the fundamental Saaty's scale (5-point scale) is implemented to facilitate the engagement of respondents who are unskilled in the use of FAHP and subsequently reduce throughout the decision-making process.

Table 1. Fuzzy 5-point scale for pairwise judgments

The phases of the FAHP method are presented below:

- Phase 1: Use the scale exhibited in Table 1 in order to compare the relative importance of criteria and sub-criteria under uncertainty. After completing all the pairwise judgments, a fuzzy reciprocal comparison matrix $\tilde{A}^{k}\left(a_{i j}\right)$ is derived as stated in Eq. 1, where $\tilde{a}_{i j}^{k}$ represents the kth decision maker's preference of ith criterion/sub-criterion over $j$ th criterion/sub-criterion.

$$
\tilde{A}^{K}=\left\{\tilde{a}_{i j}^{k}\right\}=\left[\begin{array}{cccc}
\tilde{a}_{11}^{k} & \tilde{a}_{12}^{k} & \ldots & \tilde{a}_{1 n}^{k} \\
\tilde{a}_{21}^{k} & \tilde{a}_{22}^{k} & \ldots & \tilde{a}_{2 n}^{k} \\
\ldots & \ldots & \cdots & \ldots \\
\tilde{a}_{n 1}^{k} & \tilde{a}_{n 2}^{k} & \cdots & \tilde{a}_{n n}^{k}
\end{array}\right]
$$


- Phase 2: A group decision-making process is defined to mitigate potential bias that may be introduced in the relative priorities owing to recruiting experts with different backgrounds (Naghadehi et al., 2009). In this case, the comparisons are aggregated by applying Eq. 2, where $K$ is the number of experts involved in the MCDM process. The fuzzy reciprocal comparison matrix is then updated as described in Eq. 3.

$$
\begin{aligned}
& \tilde{a}_{i j}=\sqrt[K]{\tilde{a}_{i j}^{1} * \tilde{a}_{i j}^{2} * \cdots * \tilde{a}_{i j}^{k}} \\
& \tilde{A}=\left[\begin{array}{ccc}
\tilde{a_{11}} & \cdots & \tilde{a}_{1 n} \\
\vdots & \ddots & \vdots \\
\tilde{a}_{n 1} & \cdots & \tilde{a}_{n n}
\end{array}\right]
\end{aligned}
$$

- Phase 3: Compute the geometric mean of fuzzy judgments $\left(\tilde{r}_{i}\right)$ for each criterion and sub-criterion using Eq. 4.

$$
\tilde{r}_{i}=\left(\prod_{j=1}^{n} \tilde{a}_{i j}\right)^{1 / n}, i=1,2, \ldots, n
$$

- Phase 4: Calculate the fuzzy priority of each criterion and sub-criterion $\left(\tilde{w}_{i}\right)$ by applying Eq. 5.

$$
\tilde{w}_{i}=\tilde{r}_{i} \otimes\left(\tilde{r}_{1} \oplus \tilde{r}_{2} \oplus \ldots \oplus \tilde{r}_{n}\right)^{-1}=\left(l w_{i}, m w_{i}, u w_{i}\right)
$$

- Phase 5: Defuzzify $\tilde{w}_{i}$ using the Centre of Area method (Vahidnia et al., 2009; Turskis et al., 2015) described in Eq. 6 where $M_{i}$ represents a non-fuzzy number.

$$
M_{i}=\frac{l w_{i}+m w_{i}+u w_{i}}{3}
$$

— Phase 6: Normalize $M_{i}$ values by applying Eq. 7.

$$
N_{i}=\frac{M_{i}}{\sum_{i=1}^{n} M_{i}}
$$

\subsection{Technique for Order of Preference by Similarity to Ideal Solution (TOPSIS)}

TOPSIS is a linear weighting and ranking method that has been widely employed for solving real-world MCDM problems (Sengül et al., 2015; Chen, 2015; Zavadskas et al., 2016; Ortiz- 
Barrios et al., 2017). This technique considers that the best alternative option has the shortest distance to the ideal solution (PIS) and the farthest separation to a negative ideal solution (NIS) where PIS and NIS are points within a Euclidean space. In particular, PIS is comprised of the best criterion/sub-criterion values $\left(A^{+}\right)$, whilst NIS encompasses all the worst attribute values $\left(A^{-}\right)$that can be achieved (Prakash \& Barua, 2015). Considering $A^{+}$and $A^{-}$, TOPSIS then estimates a closeness coefficient $\left(C_{i}\right)$ for each alternative (in this case, classifiers) in order to obtain a ranking where the best solution can be clearly determined (Chen, 2015). A primary criticism of the TOPSIS method is that an explicit procedure to allocate the weights of criteria/sub-criteria is not provided (Behzadian et al., 2012; Velasquez \& Hester, 2013; Ortíz-Barrios et al., 2018). This paper postulates the integration of FAHP and TOPSIS methods as an approach to overcome this inherent weakness. The TOPSIS procedure is given as follows:

- Phase 1: Set a decision matrix $X$ with " $c$ " classifiers and " $n$ " sub-criteria (Refer to Eq. 8). In this matrix, $x_{i j}$ represents the value of the sub-criterion $S C_{j}(j=1,2,3, \ldots, n)$ in each classifier $C l_{i}(i=1,2, \ldots, c)$. To obtain $x_{i j}$, a key performance metric has to be established for each sub-criterion and then measured in each classifier.

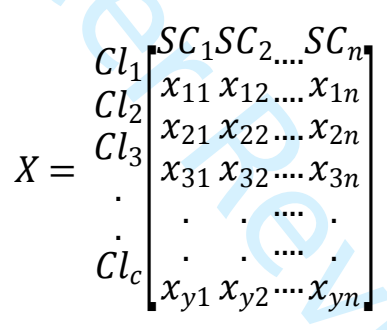

- Phase 2: Normalize matrix $X$ by transforming $x_{i j}$ into normalized values $s_{i j}$ in accordance with Eq. 9. In this formula, $n_{i j}$ is the norm employed in TOPSIS (Refer to Eq. 10).

$$
\begin{array}{r}
S=X \cdot n_{i j} \\
n_{i j}=\frac{x_{i j}}{\sqrt{\sum_{i=1}^{y} x_{i j}^{2}}}
\end{array}
$$

- Phase 3: Compute the weighted normalized decision matrix $V$ based on Eq. 11. In this formula, the weights $\left(w_{j}\right)$ derive from the FAHP method as explained above.

$$
V=\left[w_{j} s_{i j}\right]=\left[v_{i j}\right]
$$


- Phase 4: Determine the positive $\left(A^{+}\right)$and negative $\left(A^{-}\right)$extreme performance of each criterion/sub-criterion using Eq. 12-13 respectively:

$$
\begin{aligned}
& A^{+}=\left\{\left(\max _{i} s_{i j} \mid \mathrm{j} \in J\right),\left({ }_{i}^{\min } s_{i j} \mid j \in J\right) \text { for } i=1,2, \ldots, c\right\}=\left\{s_{1}^{+}, S, \ldots, S, \ldots, s\right\}
\end{aligned}
$$

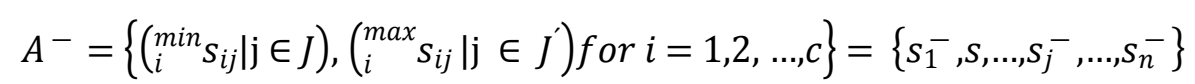

In Eq. 12-13:

$$
\begin{gathered}
J=\{j=1,2, \ldots, n \mid j \text { associated with the benefit sub-criterion/criterion }\} \\
J^{\prime}=\{j=1,2, \ldots, n \mid j \text { associated with the cost sub-criterion/criterion }\}
\end{gathered}
$$

- Phase 5: Calculate the Euclidean distance of each classifier to the positive $\left(A^{+}\right)$and negative $\left(A^{-}\right)$extreme performance by applying Eq. 14-15 correspondingly.

Euclidean distance to $A^{+}$

$$
s_{i}^{+}=\sqrt{\sum_{j=1}^{n}\left(s_{i j}-s_{j}^{+}\right)^{2}} \quad i=1,2, \ldots, c
$$

Euclidean distance to $A^{-}$

$$
s_{i}^{-}=\sqrt{\sum_{j=1}^{n}\left(s_{i j}-s_{j}^{-}\right)^{2}} \quad i=1,2, \ldots, c
$$

- Phase 6: Calculate the closeness coefficient $\left(R_{i}\right)$ for each classifier using Eq. 16. If $R_{k}$ $=1$, the classifier performance is equal to $A^{+}$. Hence, classifiers with $R_{i}$ values close to 1 are fully appreciated for supporting technology adoption in people with dementia.

$$
R_{i}=\frac{s_{i}^{+}}{\left(s_{i}^{+}+s_{i}^{-}\right)}, \quad 0 \leq R_{i} \leq 1, \quad i=1,2, \ldots, c
$$

- Phase 7: Rank the classifiers from the highest to the lowest $R_{i}$.

\section{Selecting the best classifier for the adoption of a reminding solution}

\subsection{The Scenario under Study}


Assistive technology is becoming widely accepted as a potential mechanism for supporting people with dementia, to empower them to live independently and to self-manage the symptoms of their condition for longer. Nevertheless, a one-size-fits-all approach is not appropriate in this scenario and in order to reduce the potential for of negatively impacting upon the health and economic costs associated with dementia care, it is imperative to be able to accurately recognize the compatibility, adoption likelihood and benefits of an identified assistive technology. Within this paper, we focus on predictive models assessing the suitability of an assistive technology designed to support the completion of everyday activities while maintaining a level of independence. In this case, it is necessary to identify the suitability of people with dementia when adopting a reminding solution whose primary aim is to help these people be more independent by compensating cognitive limitations. The solution is a technology that assists users via a smartphone to support self-management and medication adherence via context-aware messaging and to offer reminding support to undertake ADLs at suitable times. This contributes to diminishing the feelings of the burden faced by the carers and family members during the continuing caregiving process. Nevertheless, some barriers including limited technological experience, fear of making mistakes and misuse have to be overcome. Considering the above-mentioned aspects, predicting the adoption of this assistive technology is essential towards satisfying the needs of people with dementia and their carers as well as ensuring a correct deployment in the wild. As described within Section 4, this paper proposes an MCDM framework based on FAHP and TOPSIS techniques to explore this challenge.

\subsection{Building a decision-making team}

Faking into account Considering the aforementioned scenario, it is relevant important to select a decision-making team that provides support during the design of an MCDM framework, capable of choosing the best classification algorithm when predicting assistive technology adoption in $\mathrm{PwD}$ people with dementia. This study was previously discussed with several researchers and practitioners involved in the development and integration of reminding technologies within the everyday lives of $\mathrm{PwD}$ persens dementia. The goal of this discussion was to obtain feedback on the study perspectives and the classifiers that should be considered for the solution being investigated. The decision-making process was facilitated by two academic researchers who are co-authors of this paper. A total of seven experts, who are members of the EU funded REMIND Project consortium, were invited to participate in the MCDM process. REMIND is an international and intersectoral network whose primary aim is to advance in the creation of reminding solutions for persons with dementia to be deployed in smart environments. This consortium is composed by comprises of academic and non-academic partners who are specialized in Soft Computing, Aware 
Intelligent Systems, Artificial Intelligence, Software Engineering, Data Mining, Classification Models, Behavioural Science, Wireless Sensors Networks, Engagement with end users, principles of User Centred Design and industrial Standards for programming. A short description of the participants' profile is found below:

- Participant 1 is a Professor with extensive experience in the development and evaluation of technologies supporting the ambient assisted living. In particular, he has been involved in the research domains of mobile-based reminding solutions and technology adoption modelling. He also has the role of technical coordinator of consortia whose focus is related to aging and dementia.

- Participant 2 is a Lecturer in Data Analytics with extensive expertise in the implementation of pervasive and mobile computing technology for increasing the wellbeing and quality of life of $\mathrm{PwD}$ people with dementia.

- Participant 3 is a Senior Lecturer in Ambient Assisted Living with expertise in Behaviour Monitoring through design and deployments of Pervasive and Mobile Computing to support independent living for people with dementia and has participated as a researcher within projects funded by Alzheimer's Association.

- Participant 4 is a Professor of Image Processing with experience in the application of artificial network models in medicine and technology. In addition, he has contributed through new methods and instrument prototypes to the ongoing research in this field.

- Participant 5 is an Assistant Professor in Signal Analysis with experience in health innovation, health technology, digital electronics, and human motion analysis.

- Participants 6 and 7 are Associate Professors with significant knowledge of artificial intelligence, decision-making, pervasive and mobile computing and decision-making. Participant 7 has had sustained involvement with European projects related to eHealth and has served as an expert reviewer.

Specifically, the facilitators established a decision-making hierarchy that would assist the researchers and practitioners to identify and predict technology adoption factors for PwD persons living with dementia. In addition, they trained the team members to undertake paired comparisons employing the FAHP technique and to define key performance criteria to underpin the implementation of TOPSIS. Complementary to these activities, the participants were also invited to enrol in the decision-making team based upon their expertise to provide precise information about the evaluation criteria, which should be included in the decision process to assess a technology's suitability.

\subsection{Designing the MCDM hierarchy}


The hierarchy was discussed during $2 \times 1$-hour sessions with the participants in order to verify that the processes were appropriate, logic and understandable. As presented in Fig. 2, the final version of the MCDM model is comprised of 5 criteria, 16 sub-criteria and 7 classification algorithms (NN, DT, SVM, NB, AB, CART and, $k \mathrm{NN})$. The model was developed considering the pertinent scientific literature and expert opinion from the Consortium. The description of each criterion is consequently presented in Table 2 , which is followed by a discussion of the key observations.

Figure 2: The proposed decision-making structure for selecting the most suitable classifier for assistive technology adoption

Table 2. Description of criteria

In particular, Prediction Accuracy (SC1), defined as the proportion of correctly classified instances, was found to be one of the most commonly applied criteria when evaluating classification algorithms. On the other hand, Time Criticality (SC2) denotes the speed of classifiers when making decisions. Another sub-criteria in the performance domain is Negative Recall (SC3) which indicates the percentage of negative cases that were correctly recognized by a particular classifier from a set of negative instances. Algorithms with high Negative Recall are highly desired as these can better predict the unsuitability of the reminding solution and subsequently reduce the negative effects on the wellness of people with dementia. Apart from the above-mentioned sub-criteria, Positive Recall (SC4) was also included. This performance measure denotes the percentage of positive cases that were properly identified by a specific algorithm from a set of positive instances. In this respect, high positive recall is required for selecting dementia patients who can suitably adopt the reminding technology. Other sub-elements regarding classifiers' precision were also considered in performance area: Positive Precision (SC5) and Negative Precision (SC6). Positive Precision (SC5) is defined as the percentage of the correctly classified positive instances while Negative Precision (SC6) refers to the proportion of the correctly classified negative instances.

Regarding the Usability criterion, one of the evaluation aspects is the Ease of interpretation (SC7), which is related to the fact that a clinician must be able to somehow follow the decision steps that the classifier is making in order to have some confidence that the decision is accurate. Specific attention was attributed to the Box Type (SC8) in relation to the selected classifiers classification algorithms being regarded as black-box or white-box. White-box algorithms are often considered interpretable and may include expert knowledge whilst the internal classification logic of black-box algorithms are reported to be difficult to interpret and can therefore potentially become a barrier for supporting technology adoption. 
Under the criterion of Flexibility, it was deemed important to consider the Handling of Missing Data (SC9) based on the frequent occurrence of missing data in real-world datasets. In this regard, it was suggested that it is important that classifiers are able to robustly handle missing data in order to reduce the introduction of bias into the decision-making process. To achieve this, it was suggested to set a procedure for replacing the missing values in the dataset by approximate values derived from dependency relationships (Purwar \& Singh, 2015, Severson et al., 2017). Another aspect of interest in this domain is the Handling of Continuous and Discrete Data (SC10). The data types of the input feature space are regarded as a supporting pillar affecting the choice of a classifier for supporting the adoption of reminding solutions. Data formats need to be made compatible with the input of the modelling techniques one is going to use for solving their the task. Therefore, the model must be able to extract relevant information from these in either a discrete or continuous problem (Doquire \& Verleysen, 2011). Whether the data is discrete or continuous can also have an impact on the accuracy of the model (Sudrajat et al., 2017). The Adaption (SC11) subcriterion was also an element identified within the flexibility criterion. Particularly, this represents the necessity of having classifiers with the ability to evolve (online learning) based upon new or emerging parameters relating to the individual's needs of importance. This is highly relevant for continuously providing good support to the technology adoption process in $\mathrm{PwD}$ people with dementia and eluding potential negative impact on their wellness.

Finally, in Design criterion, several aspects of classifiers should be taken into account: Ease of data collection (SC12), Overtraining (SC13), Number of inputs (SC14), Access to validated data (SC15) and Statistical modelling (SC16). First, Ease of data collection (SC12) relates to the fact that the feature set should be either something that can be gleaned by a few simple short questions (possibly self-administered) and/or from historical data. Second, Overtraining (SC13) is a phenomenon that occurs when optimistically biased rules can provide good performance for the training dataset whilst a much lower performance ability is observed for new unknown datasets. Hence, classifiers with overtraining problems are not desired for technology adoption purposes. Third, it is assumed that classification algorithms which require fewer Inputs (SC14) are likely to be needed in this case. It is difficult to begin to consider a suitable classifier without having some understanding of the dataset that will be available; however, any models we train are likely to suffer from sparse training data. On the other hand, having access to labelled data will also inform the approach and as such Access to validated data (SC15) is an important evaluation criterion in directing the choice of classifier towards supervised, semi-supervised or clustering approaches. In addition to the above-mentioned elements, it is necessary to evaluate whether the Classifier is Statistical (SC16). Statistical classifiers are viewed as advantageous over contemporary machine learning approaches since they can yield interpretable parameters so that it is easy to identify which factors contribute the most to the prediction in addition to provide a shorter 
computation time. Conversely, some black-box machine learning methods do not offer much information on the inner workings that generate the predictions (Raudys, 2012).

\subsection{Calculating the relative weights of criteria and sub-criteria using FAHP}

A data-gathering instrument (survey) was used to collect the paired judgments produced following the FAHP method. The instrument was carefully designed (refer to Fig. 3) aiming at introducing FAHP to the participants who are not expert in MCDM techniques. After explaining the 5-point scale, presented in Table 1, the facilitators asked participants to respond to the question stated in the top part of the survey format (With respect to Goal/Criterion, how important is each element on the left over the element on the right?) by marking an option with a $X$.

Figure 3. An example of the data-gathering instrument implemented in FAHP

An illustration of a fuzzy reciprocal comparison matrix is presented in Table 3 where the judgments derived from the survey were aggregated by applying Eq. 1-3. The geometric means of fuzzy comparisons were then computed for each criterion/sub-criterion (refer to Table 4). The normalized priorities of criteria and sub-criteria were estimated after defuzzification by implementing Eq. 4 and Eq. 5-7 correspondingly (refer to Table 5). Table 6 depicts the local $(L W)$ priorities of sub-criteria as well as the global weights $(G W)$ of all the decision elements of the model (also found in Fig. 4); achieved by multiplying their local priority by the $G W$ of its respective parent criterion.

Table 3. Fuzzy reciprocal comparison matrix for criteria

Table 4. Geometric means of fuzzy comparisons for criteria

Table 5. Normalized fuzzy priorities for criteria

Table 6. LW and GW of criteria and sub-criteria

Figure 4: Ranking of criteria considering GW values

Considering the FAHP results, Scalability (C3) was considered as the criterion with the highest relative priority $(G W=0.255)$. There was not, however, a significant difference between this factor and the next three elements in the ranking (C3 vs. $\mathrm{C} 2=0.014 \| \mathrm{C} 3$ vs. $\mathrm{C} 4=0.027 \| \mathrm{C} 3$ vs. $\mathrm{C} 1=0.077$ ) which is a clear proof that these criteria should be highly prioritized when selecting classifiers. In particular, Scalability has emerged as a cornerstone in classifier selection based on the need of dealing with large amounts of data without consuming ever-increasing quantity of resources (e.g. memory). Despite this finding, little effort has been made to address scalability problems of classifiers in technology adoption of 
dementia patients which becomes a major barrier when fostering the effective implementation of assistive reminding technologies. Beyond a certain cost/practicality threshold, it is necessary to provide assisting solutions which can be deployed in the wild with minimized risk to the quality of health provided to dementia patients.

Concerning Performance (refer to Fig. 5a), the most important sub-criterion was Prediction accuracy $(L W=0.235)$. Prediction accuracy has been widely used as a performance metric for classifiers and it is therefore targeted for comparison and optimization (Vihinen, 2012; Chaurasia et al., 2016). Even though it can be puzzling in the presence of imbalanced data, this metric enables practitioners, developers, and researchers to assess the overall efficiency of the classification algorithms. Prediction accuracy then plays an important role for discriminating potential adopters and non-adopters of the reminding technology. In this regard, it is desired to count on algorithms performing accurate classification in order to avoid negative effects on dementia patients and over-expenditure due to a failed selection of the classifier. In addition, non-significant gaps $(<0.1)$ are observed between this criterion and $S C 3, S C 4, S C 5$, SC6. This demonstrates the multi-criteria nature of classifier performance and the need to simultaneously considering other metrics to assess the quality of the candidate algorithms.

\section{Figure 5. Local weights of a) performance and b) usability sub-criteria}

Considering Usability (refer to Fig. 5b), the most significant element was Ease of interpretation ( $L W=0.845$ ). Non-expert users such as clinicians and administrators are frequently overwhelmed when facing a large number of configuration options that reminding solutions may contain. In addition, comprehensibility difficulties could contribute to the failed implementation and their consequences (e.g. low long-term adoption) of such technologies in the wild. In fact, interpretability is a prerequisite for users to rely on the model predictions and effectively adhere to the derived recommendations. Thus, it is necessary to employ user-centred design methods and train unskilled users to facilitate the understanding of the classifier functioning. Thereby, the overarching effectiveness and uptake of the reminding technologies can be greatly improved in the real world which ends up increasing the market potential of these solutions. This is also consistent with the findings derived from the TAUT (Technology Adoption and Usability Testing) project where the adoption of these solutions by dementia people was further studied (Zhang, 2014).

In terms of Flexibility (refer to Fig. 6a), Handling of missing data was found to represent more than a half of importance in this criterion $(L W=0.639)$. Researchers and practitioners frequently deal with missing values in real-life scenarios. This may be caused by non- 
adherence to data management protocols and the failure/breakdown of multi-database systems. Regardless of its origin and in light of the sub-criterion relevance, classifiers should be robust to suitably incorporate this kind of data in order to avoid significant bias or false results. This directly impacts upon the ability to discriminate potential adopters and nonadopters of the reminding solution; that is, increasing the Prediction Accuracy (GarcíaLaencina et al., 2010). Depending on the pattern of missingness missing values, unknown data may be handled through imputing the values, assigning a default value or deleting observations. However, deriving the most suitable missing data treatment remains a challenging task for developers and researchers given the need for deriving highly accurate classifications.

Figure 6. Local weights of a) flexibility and b) design sub-criteria

Within the Design (refer to Fig. 6b) elements explored, Access to validated data ( $L W=$ 0.302) was the most representative criterion. In this respect, it is important to have large and validated datasets from the literature that can be used to benchmark and compare various classification models. As technology adoption is a fairly recent and emerging research topic, an appreciation for what impacts technology adoption remains limited in the literature suggesting that more data is needed to test and validate these models.

Finally, consistency values were estimated (refer to Table 7) to verify the reliability of the judgments provided by the participants. The results revealed that all matrices yielded good consistency values $(C R \leq 0.1)$. Consequently, considering the above-mentioned findings, the data-collection procedure can be regarded as robust and the outputs derived from the decision-making process can be hence concluded as highly reliable regarding the calculated priorities of criteria and sub-criteria. Besides, it is fully appreciated that consistency ratios of large-size comparison matrices, $n \geq 5$ (Criteria, Performance, and Design) were very low (< 0.04) taking into account that these matrices are more likely to be inconsistent (Barrios et al., 2014; Jarek, 2016). Indeed, as the size of the matrix increases, the inconsistency of comparisons also increases.

Table 7. Consistency values for FAHP matrices

\subsection{Ranking the classifiers through TOPSIS method}

This section describes Phase 5 of the methodology presented within this paper. by By reporting upon the application of the TOPSIS method to rank the candidate classifiers that were identified for supporting the technology adoption of a reminding solution in PwD 
people with dementia. Specifically, as presented in Table 8, an indicator was established for each sub-element (note: Scalability was considered here since there are no sub-criteria within this cluster). Subsequently, Eq. 8 was applied to derive the initial decision matrix, $X$ (refer to Table 9) where the candidate classifiers $\left(\mathrm{Cl}_{1}, \mathrm{Cl}_{2}, \mathrm{Cl}_{3}, \mathrm{Cl}_{4}, \mathrm{Cl}_{5}, \mathrm{Cl}_{6}, \mathrm{Cl}_{7}\right)$ were associated with the decision elements. The values of these elements were introduced in matrix $X$ based on the description provided in Table 8 .

Table 8. Indicators for the decision elements

Ideal $\left(A^{+}\right)$and anti-ideal $\left(A^{-}\right)$extreme attribute values are also presented in Table 9 applying Eq. 12 and Eq. 13, respectively. The normalized TOPSIS decision matrix $S$ is presented in Table 10 using Eq. 9-10. The weighted normalized decision matrix $V$ (refer to Table 11) was calculated by implementing Eq. 11. In this matrix, the relative priorities of sub-criteria were obtained through the FAHP technique (refer to sub-section 5.4). The Euclidean distance of each classifier $\left(\mathrm{Cl}_{1}, \mathrm{Cl}_{2}, \mathrm{Cl}_{3}, \mathrm{Cl}_{4}, \mathrm{Cl}_{5}, \mathrm{Cl}_{6}, \mathrm{Cl}_{7}\right)$ to the positive extreme performance is computed using Eq. 14 (refer to Table 12). Likewise, the separation of each classifier from the negative ideal scenario $\left(S_{i}^{-}\right)$is calculated by applying Eq. 15 (refer to Table 13).

Table 9. Initial decision matrix $X$ for selecting the most suitable classifier for supporting technology adoption in people with dementia.

Table 10. Normalized TOPSIS decision matrix $S$ for selecting the most suitable classifier for supporting technology adoption in people with dementia.

Table 11. Weighted normalized decision matrix $V$ for selecting the most suitable classifier for supporting technology adoption in people with dementia.

Table 12. Euclidean distance to the positive extreme performance

Table 13. Euclidean distance to the negative extreme performance

The ranking of candidate classification algorithms and their closeness coefficients $R_{i}$ are presented in Figure 47. $R_{i}$ values were computed by implementing Eq.16. Based upon these outputs, it can be noted that KNN was categorized as the most suitable classifier for supporting the adoption of the reminding solution described in Subsection 5.1 with $R_{7}$ $=0.804$. In turn, SVM achieved the lowest score $R_{3}=0.201$ and it is not therefore recommended for effectively discriminating between adopters and non-adopters. In addition to these findings, when analyzing the distance measures provided in Table 12 and Table 13 and specifically the strong (sub-criteria/criteria whose Euclidean separation to $A^{+}$is equal to 0 ) and weak points of each candidate classifier (sub-criteria/criteria whose Euclidean 
separation to $A^{+}$is greater than zero $\|$separation to $A^{-}$is equal to 0 ), it can be concluded that CART provides the largest computational time (SC2 $=467.25 \mathrm{~min} \|$ Separation from $s_{2}^{+}$ $=0.013$ ) compared to the rest of classifiers. Algorithms with this drawback are inefficient and costly in practical scenarios as they slow down the decision-making process. Therefore, CART is not recommended for supporting the adoption of the reminding solution here described. In addition, CART was found to offer the lowest positive recall $(\mathrm{SC} 4=13.28 \% \|$ Separation from $\left.s_{4}^{+}=0.013\right)$ and positive precision $\left(\mathrm{SC} 5=13.28 \% \|\right.$ Separation from $s_{5}^{+}=$ 0.015). This means that CART does not have a good ability for identifying the potential adopters who will benefit from the reminding solution. Hence, this classifier cannot help clinicians to detect identify the opportunity of employing deploying this assistive technology for supporting independent living and self-management of the symptoms inherent in dementia.

On the other hand, DT, NN, SVM, and AB were concluded to be difficult to interpret by nonexperts; i.e., healthcare professionals (SC7 $=1 \|$ Separation from $\left.s_{7}^{+}=0.046\right)$. Therefore, these classifiers are and it is not thus useful nor efficient for implementation in the wild as these professionals clinicians may often feel unconfident regarding the decision accuracy and uncomfortable due to its complex decision procedure. NB, SVM and AB were found to be non-scalable classifiers considering the high cost of its the learning process $(\mathrm{C} 3=1 \|$ Separation from $s_{c 3}^{+}=0.066$ ). This is of particular interest for developers who also seek low resource-consuming technologies that can be deployed with high competitiveness within the healthcare systems. With respect to Handling of missing data (SC9), SVM was found to be worst classifier $\left(\mathrm{SC} 9=1 \|\right.$ Separation from $\left.s_{9}^{+}=0.031\right)$. This is critical in a sector where missing data can be often be encountered in clinical records and robust classifiers are thus highly required for supporting the adoption of assistive technologies.

Figure 47. Ranking of classification algorithms identified as candidates for supporting the technology adoption in people with dementia

\section{Conclusions}

This paper presents a hybrid fuzzy AHP-TOPSIS method for selecting the most suitable classifier to support and maintain assistive technology adoption in PwD people with dementia. It has aimed to address previous criticisms of single MCDM methods by providing objective traceability in the technology adoption decision process. It goes beyond earlier approaches such as TAM and PIADs that have been questioned in relation to their heuristic value and lack of explanatory power, in particular, by employing an additional knowledge driven perspective to technology adoption. This has afforded the potential to assist with the 
overarching aim of making models transferable to different users, and to different technology-based domains.

Two key contributions arise from this work. The primary contribution of this work has been the identification of the most relevant criteria for selecting a suitable classifier that can be employed to pair relevant assistive technology with $\mathrm{PwD}$ people living with dementia, based upon their health status, and likelihood to adopt. This has involved taking into consideration characteristics related to performance, usability, scalability, flexibility, and design of various assistive technologies. This is an important development towards maximizing the role that assistive technology offers in providing complementary care to $\mathrm{PwD}$ people with dementia by enhancing the ability to accurately predict the adoption likelihood by a particular person thereby ensuring the best possible technology fit.

A secondary contribution of this work has been the proposal of a formal process for capturing domain expertise about a specific problem area, towards formalizing the key factors in the design and development of optimized classification models. While the paper has focused upon a particular use case, which surrounds assistive technology adoption in dementia care, the processes outlined herein could be adapted to support many applications where there is a requirement to extract and embedded detailed domain knowledge, captured from human experts towards designing and developing a set of automated classification processes.

Future work within the overarching REMIND project will seek to determine the feasibility of explore exploring the objective assessment of the models established within this paper. Indeed, there is scope to develop an intuitive development of an interactive mobile-based assessment tool that can, underpinned by the models established within this paper, to provide empower service providers to undertake a real time technology adoption likelihood assessment service for people living with dementia-, based on a data entry of a modest set of input parameters. Results obtained from a feasibility study would be used to further complement and enhance the models proposed within this paper.

\section{Acknowledgments}

This work was funded by the Research and Innovation Staff Exchange (RISE) program from the European Commission under the call: H2020-MSCA-RISE-2016. The authors would also like to thank Giusseppe Polifroni Avendaño for his contribution to this work.

\section{References}


Aires, R. F. D. F., \& Ferreira, L. (2018). THE RANK REVERSAL PROBLEM IN MULTICRITERIA DECISION MAKING: A LITERATURE REVIEW. Pesquisa Operacional, 38(2), 331-362.

Barrios, M. O., Jiménez, H. F., \& Isaza, S. N. (2014, December). Comparative analysis between ANP and ANP-DEMATEL for six sigma project selection process in a healthcare provider. In International Workshop on Ambient Assisted Living (pp. 413-416). Springer, Cham.

Barrios, M. A. O., De Felice, F., Negrete, K. P., Romero, B. A., Arenas, A. Y., \& Petrillo, A. (2016). An AHP-topsis integrated model for selecting the most appropriate tomography equipment. International Journal of Information Technology \& Decision Making, 15(04), 861-885.

Behzadian, M., Otaghsara, S.K., Yazdani, M. and Ignatius, J. (2012), “A state-of the-art survey of TOPSIS applications”, Expert Systems with Applications, Vol. 39 No. 17, pp. 13051-13069.

Bendaoud, F., Didi, F., \& Abdennebi, M. (2017). A modified-SAW for network selection in heterogeneous wireless networks. ECTI Transactions on Electrical Engineering, Electronics, and Communications, 15(2), 8-17.

Bevan, N., Carter, J., \& Harker, S. (2015, August). ISO 9241-11 revised: What have we learnt about usability since 1998?. In International Conference on Human-Computer Interaction (pp. 143-151). Springer, Cham.

Chadha, R., Mayank, S., Vardhan, A., \& Pradhan, T. (2016). Application of data mining techniques on heart disease prediction: a survey. In Emerging Research in Computing, Information, Communication and Applications (pp. 413-426). Springer, New Delhi.

Chaurasia, P., McClean, S. I., Nugent, C. D., Cleland, I., Zhang, S., Donnelly, M. P., ... \& Tschanz, J. (2016). Modelling assistive technology adoption for people with dementia. Journal of biomedical informatics, 63, 235-248.

Chaurasia, P., McClean, S. I., Nugent, C. D., Cleland, I., Zhang, S., Donnelly, M. P., ... \& Tschanz, J. (2016, August). Technology adoption and prediction tools for everyday technologies aimed at people with dementia. In Engineering in Medicine and Biology Society (EMBC), 2016 IEEE 38th Annual International Conference of the (pp. 4407-4410). IEEE.

Chen, T. Y. (2015). The inclusion-based TOPSIS method with interval-valued intuitionistic fuzzy sets for multiple criteria group decision making. Applied Soft Computing, 26, 57-73. 
Cho, J., \& Lee, J. (2013). Development of a new technology product evaluation model for assessing commercialization opportunities using Delphi method and fuzzy AHP approach. Expert Systems with Applications, 40(13), 5314-5330.

Chuttur, M. Y. (2009). Overview of the technology acceptance model: Origins, developments and future directions. Working Papers on Information Systems, 9(37), 9-37.

Cook, E. J., Randhawa, G., Sharp, C., Ali, N., Guppy, A., Barton, G., ... \& Crawford-White, J. (2016). Exploring the factors that influence the decision to adopt and engage with an integrated assistive telehealth and telecare service in Cambridgeshire, UK: a nested qualitative study of patient 'users' and 'non-users'. BMC health services research, 16(1), 137.

Czarnuch, S., Ricciardelli, R., \& Mihailidis, A. (2016). Predicting the role of assistive technologies in the lives of people with dementia using objective care recipient factors. $B M C$ geriatrics, 16(1), 143.

Dağdeviren, M., \& Yüksel, İ. (2008). Developing a fuzzy analytic hierarchy process (AHP) model for behavior-based safety management. Information sciences, 178(6), 1717-1733.

Day, H. (1996). Measuring the psychosocial impact of assistive devices: the PIADS. Canadian Journal of Rehabilitation, 9(2), 159-168.

Doquire, G., \& Verleysen, M. (2011, October). An Hybrid Approach to Feature Selection for Mixed Categorical and Continuous Data. In KDIR (pp. 394-401).

Ertuğrul, İ., \& Karakaşoğlu, N. (2009). Performance evaluation of Turkish cement firms with fuzzy analytic hierarchy process and TOPSIS methods. Expert Systems with Applications, 36(1), 702-715

García-Laencina, P. J., Sancho-Gómez, J. L., \& Figueiras-Vidal, A. R. (2010). Pattern classification with missing data: a review. Neural Computing and Applications, 19(2), 263282.

Guan, S. S. A., Bui, T. A., \& Ho, W. (2017). Considering Cultural Factors in Emerging Adult Use of Communication Technologies: Culture in Technology Use. International Journal of Information Communication Technologies and Human Development (IJICTHD), 9(3), 1428.

Huang, R., \& Li, Y. (2013). Undesirable input-output two-phase DEA model in an environmental performance audit. Mathematical and Computer Modelling, 58(5-6), 971979. 
Ishizaka, A., \& Labib, A. (2009). Analytic hierarchy process and expert choice: Benefits and limitations. Or Insight, 22(4), 201-220.

Ishizaka A. Comparison of fuzzy logic, AHP, FAHP and hybrid fuzzy AHP for new supplier selection and its performance analysis. International Journal of Integrated Supply Management. 2014;9:1-22.

ISO/TC 159/SC 4 Ergonomics of human-system interaction (2018) ISO 9241-11:2018 Ergonomics of human-system interaction - Part 11: Usability: Definitions and concepts, Vol. 2. International Organization for Standardization.

Izquierdo, N. V., Viloria, A., Gaitán-Angulo, M., Bonerg, O., Lezama, P., Erase, J. J. C., \& Gutiérrez, A. S. (2016). Methodology of application of diffuse mathematics to performance evaluation. International Journal of Control Theory and Applications. ISSN, 0974-5572.

Jarek, S. (2016). Removing Inconsistency in Pairwise Comparisons Matrix in the AHP. Multiple Criteria Decision Making, 11, 63-76.

Kumar, S., \& Haleem, A. (2015). Evaluating bullwhip effect mitigation: an analytical network process (ANP) application. International Journal of advanced Research in Engineering Science and Management, 2(1), 1-14.

Lee, C., \& Coughlin, J. F. (2015). PERSPECTIVE: Older adults' adoption of technology: an integrated approach to identifying determinants and barriers. Journal of Product Innovation Management, 32(5), 747-759.

Lin, S. W. (2017). Identifying the critical success factors and an optimal solution for mobile technology adoption in travel agencies. International Journal of Tourism Research, 19(2), 127-144.

Mardani A, Jusoh A, Zavadskas E. Fuzzy multiple criteria decision-making techniques and applications - Two decades review from 1994 to 2014. Expert Systems with Applications. 2015; 42:4126-48.

Midhunchakkaravarthy, J., \& Brunda, S. S. (2016). An Enhanced Web Mining Approach for Product Usability Evaluation in Feature Fatigue Analysis using LDA Model and Association Rule Mining with Fruit Fly Algorithm. Indian Journal of Science and Technology, 9(8).

Miskovic, V., \& Babic, D. (2016). Implementation of a Flexible Bayesian Classifier for the Assessment of Patient's Activities within a Real-time Personalized Mobile Application. Engineering, Technology \& Applied Science Research, 7(1), 1405-1412. 
Naghadehi, M. Z., Mikaeil, R., \& Ataei, M. (2009). The application of fuzzy analytic hierarchy process (FAHP) approach to selection of optimum underground mining method for Jajarm Bauxite Mine, Iran. Expert Systems with Applications, 36(4), 8218-8226.

Ortiz-Barrios, M. A., Herrera-Fontalvo, Z., Rúa-Muñoz, J., Ojeda-Gutiérrez, S., De Felice, F., \& Petrillo, A. (2018). An integrated approach to evaluate the risk of adverse events in hospital sector: From theory to practice. Management Decision, 56(10), 2187-2224.

Ortiz-Barrios, M. A., Aleman-Romero, B. A., Rebolledo-Rudas, J., Maldonado-Mestre, H., Montes-Villa, L., De Felice, F., \& Petrillo, A. (2017). The analytic decision-making preference model to evaluate the disaster readiness in emergency departments: The ADT model. Journal of Multi-Criteria Decision Analysis, 24(5-6), 204-226.

Ortiz-Barrios, M. A., Kucukaltan, B., Carvajal-Tinoco, D., Neira-Rodado, D., \& Jiménez, G. (2017). Strategic hybrid approach for selecting suppliers of high-density polyethylene. Journal of Multi-Criteria Decision Analysis, 24(5-6), 296-316.

Phan, K., \& Daim, T. U. (2011). Exploring technology acceptance for mobile services. Journal of Industrial Engineering and Management.

Prakash, C., \& Barua, M. K. (2015). Integration of AHP-TOPSIS method for prioritizing the solutions of reverse logistics adoption to overcome its barriers under fuzzy environment. Journal of Manufacturing Systems, 37, 599-615.

Purwar, A., \& Singh, S. K. (2015). Hybrid prediction model with missing value imputation for medical data. Expert Systems with Applications, 42(13), 5621-5631.

Raudys, S. (2012). Statistical and Neural Classifiers: An integrated approach to design. Springer Science \& Business Media.

Robillard, J. M., Cleland, I., Hoey, J., \& Nugent, C. (2018). Ethical adoption: A new imperative in the development of technology for dementia. Alzheimer's \& Dementia.

Rodríguez, A., Ortega, F., \& Concepción, R. (2016). A method for the evaluation of risk in IT projects. Expert Systems with Applications, 45, 273-285.

Saaty, T. L. (2013). Analytic hierarchy process. In Encyclopedia of operations research and management science (pp. 52-64). Springer, Boston, MA.

Saaty, T. L., \& Vargas, L. G. (2012). Models, methods, concepts \& applications of the analytic hierarchy process (Vol. 175). Springer Science \& Business Media. 
Şengül, Ü., Eren, M., Shiraz, S. E., Gezder, V., \& Şengül, A. B. (2015). Fuzzy TOPSIS method for ranking renewable energy supply systems in Turkey. Renewable Energy, 75, 617625.

Severson, K. A., Monian, B., Love, J. C., \& Braatz, R. D. (2017). A method for learning a sparse classifier in the presence of missing data for high-dimensional biological datasets. Bioinformatics, 33(18), 2897-2905.

Sharma, R., \& Mishra, R. (2014). A review of evolution of theories and models of technology adoption. Indore Manag. J, 6(2), 17-29.

Shaverdi, M., Heshmati, M. R., \& Ramezani, I. (2014). Application of fuzzy AHP approach for financial performance evaluation of Iranian petrochemical sector. Procedia Computer Science, 31, 995-1004.

Shieh, L. F., Chang, T. H., Fu, H. P., Lin, S. W., \& Chen, Y. Y. (2014). Analyzing the factors that affect the adoption of mobile services in Taiwan. Technological Forecasting and Social Change, 87, 80-88.

Shin, Y. B., Lee, S., Chun, S. G., \& Chung, D. (2013). A critical review of popular multicriteria decision making methodologies. Issues in Information Systems, 14(1), 358-365.

Shin, Y. B. (2017). Rank reversal phenomenon in cross-efficiency evaluation of data envelopment analysis. International Journal of Business and Economic Development (IJBED), 5(1).

Shore, L., Power, V., de Eyto, A., \& O’Sullivan, L. W. (2018). Technology Acceptance and User-Centred Design of Assistive Exoskeletons for Older Adults: A Commentary. Robotics, 7(1), 3.

Soltanifar, M., \& Shahghobadi, S. (2014). Survey on rank preservation and rank reversal in data envelopment analysis. Knowledge-Based Systems, 60, 10-19.

Spreicer, W. (2011, June). Tangible interfaces as a chance for higher technology acceptance by the elderly. In Proceedings of the 12th International Conference on Computer Systems and Technologies (pp. 311-316). ACM.

Sudrajat, R., Irianingsih, I., \& Krisnawan, D. (2017, January). Analysis of data mining classification by comparison of C4. 5 and ID algorithms. In IOP Conference Series: Materials Science and Engineering (Vol. 166, No. 1, p. 012031). IOP Publishing. 
Turskis, Z., Zavadskas, E. K., Antucheviciene, J., \& Kosareva, N. (2015). A hybrid model based on fuzzy AHP and fuzzy WASPAS for construction site selection. International Journal of Computers Communications \& Control, 10(6), 113-128.

Vahidnia, M. H., Alesheikh, A. A., \& Alimohammadi, A. (2009). Hospital site selection using fuzzy AHP and its derivatives. Journal of environmental management, 90(10), 30483056 .

Velasquez, M. and Hester, P.T. (2013), "An analysis of multi-criteria decision making methods", International Journal of Operations Research, Vol. 10 No. 2, pp. 56-66.

Venkatesh, V., \& Davis, F. D. (2000). A theoretical extension of the technology acceptance model: Four longitudinal field studies. Management science, 46(2), 186-204.

Venkatesh, V., Morris, M. G., Davis, G. B., \& Davis, F. D. (2003). User acceptance of information technology: Toward a unified view. MIS quarterly, 425-478.

Venkatesh, V., Thong, J. Y., Chan, F. K., Hu, P. J. H., \& Brown, S. A. (2011). Extending the two-stage information systems continuance model: Incorporating UTAUT predictors and the role of context. Information Systems Journal, 21(6), 527-555.

Vihinen, M. (2012, June). How to evaluate performance of prediction methods? Measures and their interpretation in variation effect analysis. In BMC genomics (Vol. 13, No. 4, p. S2). BioMed Central.

Wang, C.H., Pang, C.T., 2011. Using VIKOR Method for Evaluating Service Quality of Online Auction under Fuzzy Environment. International Journal of Computer Science \& Engineering Technology, 1(6), 307-314.

Yadegaridehkordi, E., Nasir, M. H. N. B. M., Noor, N. F. B. M., Shuib, L., \& Badie, N. (2018). Predicting the adoption of cloud-based technology using fuzzy analytic hierarchy process and structural equation modelling approaches. Applied Soft Computing, 66, 77-89.

Zavadskas, E. K., Mardani, A., Turskis, Z., Jusoh, A., \& Nor, K. M. (2016). Development of TOPSIS method to solve complicated decision-making problems-An overview on developments from 2000 to 2015. International Journal of Information Technology \& Decision Making, 15(03), 645-682.

Zhang, S., McClean, S. I., Nugent, C. D., Donnelly, M. P., Galway, L., Scotney, B. W., \& Cleland, I. (2014). A predictive model for assistive technology adoption for people with dementia. IEEE journal of biomedical and health informatics, 18(1), 375-383. 


\section{List of figures}

GOAL: To select the most suitable classifier for supporting assistive technology adoption in people with dementia

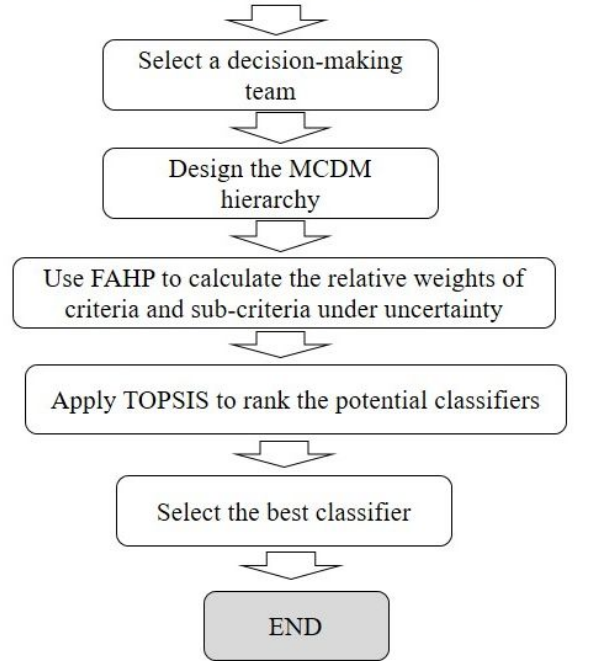

Figure 1: The five-phase methodology for selecting the most suitable classifier for supporting assistive technology adoption in people with dementia. 


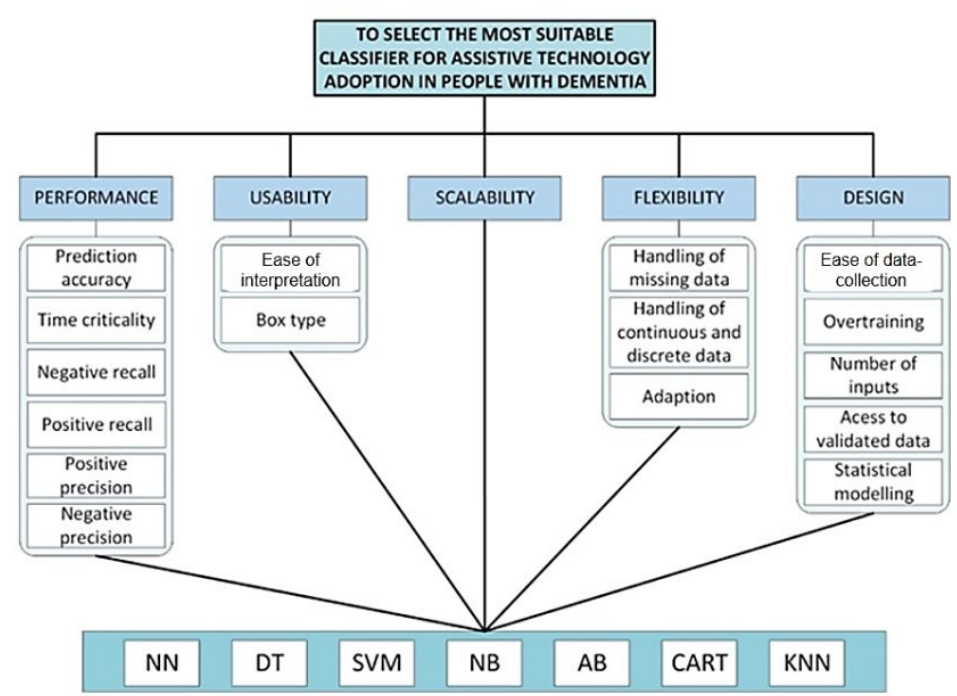

Figure 2: The proposed decision-making structure for selecting the most suitable classifier for assistive technology adoption

\begin{tabular}{|c|c|c|c|c|c|c|c|c|}
\hline \multicolumn{9}{|c|}{ With respect to "Flexibility", ¿how important is each element on the left over the element on the right } \\
\hline & & 1 & 2 & 3 & 4 & 5 & & \\
\hline Handling of missing data & is & $\square$ & $\square$ & $\square$ & $\square$ & $\square$ & Important than & $\begin{array}{l}\text { Handling of continuous } \\
\text { and discrete data }\end{array}$ \\
\hline Handling of missing data & is & $\square$ & $\square$ & $\square$ & $\square$ & $\square$ & Important than & Adaption \\
\hline $\begin{array}{c}\text { Handling of continuous } \\
\text { and discrete data }\end{array}$ & is & $\square$ & $\square$ & $\square$ & $\square$ & $\square$ & Important than & Adaption \\
\hline \multicolumn{8}{|c|}{1 Much less 3 Equally } & \multirow[t]{2}{*}{5 Much more } \\
\hline 2 Less & & & 4 & More & & & & \\
\hline
\end{tabular}

Figure 3: An example of the data-gathering instrument implemented in FAHP



Figure 4: Ranking of criteria considering GW values 


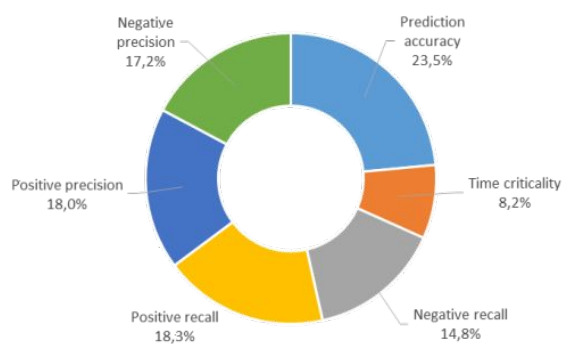

(a)

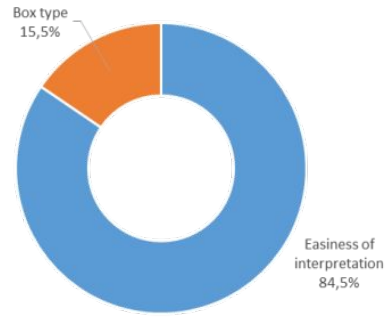

(b)

Figure 5. Local weights of a) performance and b) usability sub-criteria

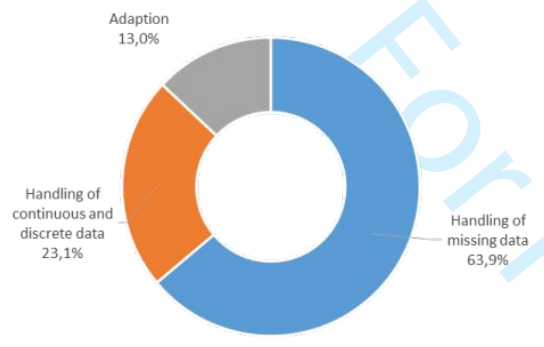

(a)

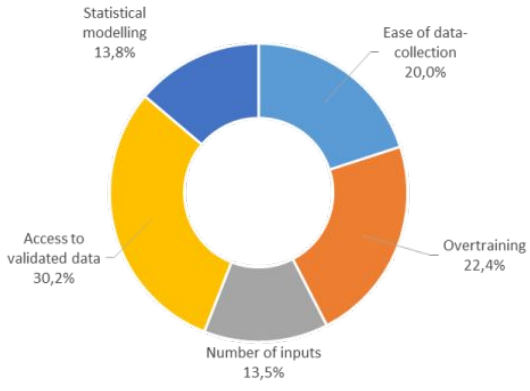

(b)

Figure 6. Local weights of a) flexibility and b) design sub-criteria

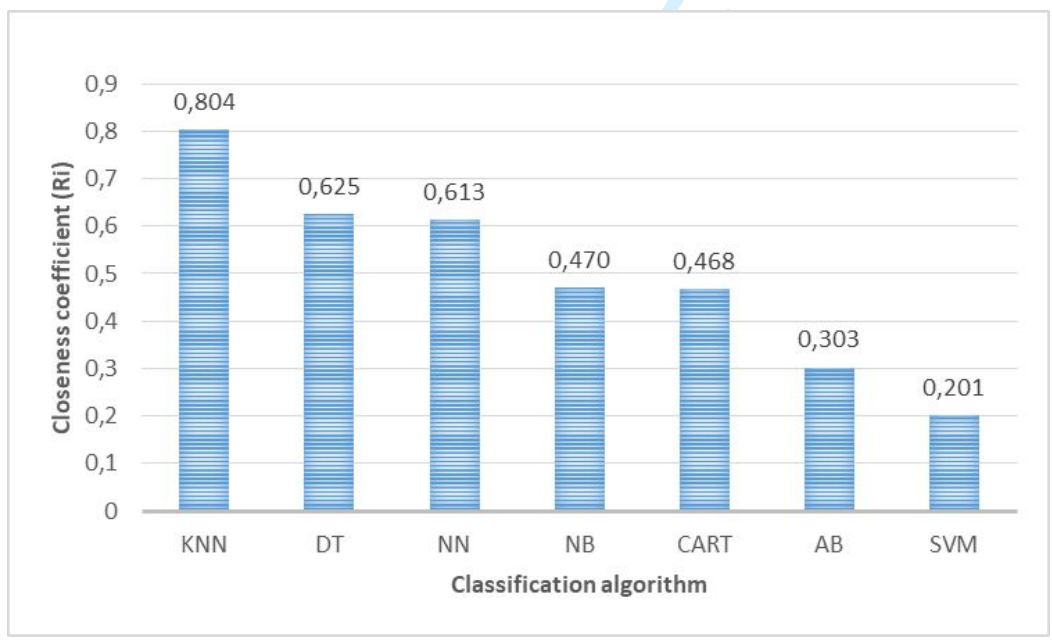

Figure 4-7: Ranking of classification algorithms identified as candidates for supporting the technology adoption in people with dementia

\section{List of tables}

Table 1. Fuzzy 5-point scale for pairwise judgments 


\begin{tabular}{|c|l|c|}
\hline 5-point scale & Description & Fuzzy triangular number \\
\hline $\mathbf{1}$ & Equally important & {$[1,1,1]$} \\
\hline $\mathbf{3}$ & More important & {$[2,3,4]$} \\
\hline $\mathbf{5}$ & Much more important & {$[4,5,6]$} \\
\hline $\mathbf{1 / 3}$ & Less important & {$[1 / 4,1 / 3,1 / 2]$} \\
\hline $\mathbf{1 / 5}$ & Much less important & {$[1 / 6,1 / 5,1 / 4]$} \\
\hline
\end{tabular}

Table 2. Description of criteria

\begin{tabular}{|c|c|c|}
\hline Criterion (C) & Sub-criteria (SC) & Criterion description \\
\hline Performance $(\mathrm{C} 1)$ & $\begin{array}{l}\text { Prediction accuracy (SC1) } \\
\text { Time criticality (SC2) } \\
\text { Negative recall (SC3) } \\
\text { Positive recall (SC4) } \\
\text { Positive precision (SC5) } \\
\text { Negative precision (SC6) }\end{array}$ & $\begin{array}{l}\text { It is defined as the predictive ability of a } \\
\text { classification algorithm for establishing whether } \\
\text { people with dementia can adopt an assistive } \\
\text { technology (Zhang et al., 2014). }\end{array}$ \\
\hline Usability (C2) & $\begin{array}{l}\text { Ease of interpretation (SC7) } \\
\text { Box type (SC8) }\end{array}$ & $\begin{array}{l}\text { According to the ISO 9241-11 (2018), the usability } \\
\text { is the extent to which a system, product or service } \\
\text { can be used by specified users to achieve specified } \\
\text { goals with effectiveness, efficiency, and satisfaction } \\
\text { in a specified context of use" This criterion then } \\
\text { assesses whether the classification algorithm is easy } \\
\text { to comprehend. From this perspective, healthcare } \\
\text { staff and users need to be capable of effectively } \\
\text { employing the results derived from the classifier. } \\
\text { This is even more relevant when considering people } \\
\text { with no technical and computational skills (Bevan } \\
\text { et al., 2015; Midhunchakkaravarthy and Brunda, } \\
\text { 2016) }\end{array}$ \\
\hline Scalability (C3) & Without sub-criteria & $\begin{array}{l}\text { This factor considers how costly the learning } \\
\text { process of a classifier is. In this respect, it is } \\
\text { important to evaluate if it is necessary to include } \\
\text { new samples or eliminate others from the dataset. } \\
\text { Lazy classifiers are then concluded to have high } \\
\text { scalability (Chada et al., 2016). }\end{array}$ \\
\hline Flexibility (C4) & $\begin{array}{l}\text { Handling of missing data (SC9) } \\
\text { Handling of continuous and } \\
\text { discrete data (SC10) } \\
\text { Adaption (SC11) }\end{array}$ & $\begin{array}{l}\text { Flexibility measures the response of a classifier } \\
\text { considering the fact that the time-window for } \\
\text { assistive technology is quite short for people with } \\
\text { dementia and the suitability of different } \\
\text { technologies will change rapidly over time } \\
\text { (Miskovic and Babic, 2016). }\end{array}$ \\
\hline Design (C5) & $\begin{array}{l}\text { Ease of data-collection (SC12) } \\
\text { Overtraining (SC13) } \\
\text { Number of inputs (SC14) } \\
\text { Access to validated data (SC15) } \\
\text { Statistical modelling (SC16) }\end{array}$ & $\begin{array}{l}\text { Design encompasses all the classifier characteristics } \\
\text { regarding data collection, modelling, and } \\
\text { management. }\end{array}$ \\
\hline
\end{tabular}


Table 3. Fuzzy reciprocal comparison matrix for criteria

\begin{tabular}{|l|l|l|l|l|l|}
\hline & C1 & C2 & C3 & C4 & C5 \\
\hline C1 & {$[1,1,1]$} & {$[0.66,0.80,1.00]$} & {$[0.80,0.90,1.00]$} & {$[0.92,1.12,1.32]$} & {$[0.76,1.00,1.32]$} \\
\hline C2 & {$[1.00,1.25,1.52]$} & {$[1,1,1]$} & {$[0.80,1.12,1.52]$} & {$[0.70,0.90,1.15]$} & {$[1.74,2.14,2.49]$} \\
\hline C3 & {$[1.00,1.11,1.25]$} & {$[0.66,0.89,1.25]$} & {$[1,1,1]$} & {$[1.22,1.55,1.89]$} & {$[1.52,2.14,2.86]$} \\
\hline C4 & {$[0.76,0.89,1.18]$} & {$[0.87,1.11,1.43]$} & {$[0.53,0.64,0.82]$} & {$[1,1,1]$} & {$[2.64,3.27,3.87]$} \\
\hline C5 & {$[0.76,1.00,1.32]$} & {$[0.40,0.47,0.57]$} & {$[0.35,0.47,0.66]$} & {$[0.26,0.31,0.38]$} & {$[1,1,1]$} \\
\hline
\end{tabular}

Table 4. Geometric means of fuzzy comparisons for criteria

\begin{tabular}{|l|c|c|c|c|c|}
\hline Criterion & C1 & C2 & C3 & C4 & C5 \\
\hline $\begin{array}{l}\text { Geometric mean of } \\
\text { fuzzy comparisons }\end{array}$ & {$[0.78,0.95,1.15]$} & {$[0.99,1.28,1.60]$} & {$[1.05,1.34,1.70]$} & {$[0.98,1.20,1.49]$} & {$[0.41,0.51,0.66]$} \\
\hline
\end{tabular}

Table 5. Normalized fuzzy priorities for criteria

\begin{tabular}{|l|l|l|l|c|c|}
\hline Fuzzy weight & \multicolumn{2}{|c|}{ Non-fuzzy weight } & Normalized weight \\
\hline C1 & 0.12 & 0.18 & 0.27 & 0.19 & 0.178 \\
\hline C2 & 0.15 & 0.24 & 0.38 & 0.26 & 0.241 \\
\hline C3 & 0.16 & 0.25 & 0.40 & 0.27 & 0.255 \\
\hline C4 & 0.15 & 0.23 & 0.35 & 0.24 & 0.228 \\
\hline C5 & 0.06 & 0.10 & 0.16 & 0.10 & 0.098 \\
\hline Total & & 1.07 & 1 \\
\hline
\end{tabular}

Table 6. LW and GW of criteria and sub-criteria

\begin{tabular}{|c|c|c|}
\hline Cluster & GW & LW \\
\hline Performance (C1) & 0.178 & \\
\hline Prediction accuracy (SC1) & 0.042 & 0.235 \\
\hline Time criticality (SC2) & 0.015 & 0.082 \\
\hline Negative recall (SC3) & 0.026 & 0.148 \\
\hline Positive recall (SC4) & 0.033 & 0.183 \\
\hline Positive precision (SC5) & 0.032 & 0.180 \\
\hline Negative precision (SC6) & 0.031 & 0.172 \\
\hline Usability (C2) & 0.241 & \\
\hline Ease of interpretation (SC7) & 0.204 & 0.845 \\
\hline Box type (SC8) & 0.037 & 0.155 \\
\hline Scalability (C3) & 0.255 & \\
\hline Flexibility (C4) & 0.228 & \\
\hline Handling of missing data (SC9) & 0.145 & 0.639 \\
\hline Handling of continuous and discrete data (SC10) & 0.053 & 0.231 \\
\hline Adaption (SC11) & 0.030 & 0.130 \\
\hline Design (C5) & 0.098 & \\
\hline Ease of data-collection (SC12) & 0.020 & 0.200 \\
\hline
\end{tabular}


Overtraining (SC13)

Number of inputs (SC14)

0.013

0.135

Access to validated data (SC15)

0.030

0.302

Statistical modelling (SC16)

0.014

0.138

Table 7. Consistency values for FAHP matrices

\begin{tabular}{cc}
\hline Cluster & $\begin{array}{c}\text { Consistency } \\
\text { ratio (CR) }\end{array}$ \\
\hline Criteria & 0.0370 \\
Performance & 0.0023 \\
Usability & 0 \\
Flexibility & 0.0559 \\
Design & 0.0140
\end{tabular}

Table 8. Indicators for the decision elements

\begin{tabular}{|c|c|c|}
\hline $\begin{array}{l}\text { Decision } \\
\text { element }\end{array}$ & Indicator & Mathematical formula \\
\hline $\begin{array}{c}\text { Prediction } \\
\text { accuracy (SC1) }\end{array}$ & Accuracy & $\begin{array}{l}\qquad \text { Accuracy }=\frac{T N+T P}{T P+F P+F N+T N} * 100 \\
\text { Where: } \\
\text { TN: True negative classifications } \\
\text { TP: True positive classifications } \\
\text { FP: False positive classifications } \\
\text { FN: False negative classifications }\end{array}$ \\
\hline $\begin{array}{l}\text { Time criticality } \\
\text { (SC2) }\end{array}$ & $\begin{array}{l}\text { Average computational } \\
\text { time }\end{array}$ & $\begin{array}{l}\text { CT }{ }_{i} \text { :computational time in } \\
\text { interation } i\end{array}$ \\
\hline $\begin{array}{l}\text { Negative recall } \\
\text { (SC3) }\end{array}$ & Recall (-) & $\begin{array}{l}\qquad \operatorname{Recall}(-)=\frac{\mathrm{TN}}{\mathrm{TN}+\mathrm{FP}} * 100 . \\
\text { Where: } \\
\text { TN: True negative classifications } \\
\text { FP: False positive classifications }\end{array}$ \\
\hline $\begin{array}{l}\text { Positive recall } \\
\text { (SC4) }\end{array}$ & Recall (+) & $\begin{array}{l}\qquad \operatorname{Recall}(+)=\frac{T P}{T P+F N} * 100 \\
\text { Where: } \\
\text { TP: True positive classifications } \\
\text { FN: False negative classifications }\end{array}$ \\
\hline $\begin{array}{l}\text { Positive precision } \\
\text { (SC5) }\end{array}$ & Precision $(+)$ & $\begin{array}{l}\qquad \operatorname{Precision}(+)=\frac{\mathrm{TP}}{\mathrm{TP}+\mathrm{FP}} * 100 \\
\text { Where: } \\
\text { TP: True positive classifications } \\
\text { FP: False positive classifications }\end{array}$ \\
\hline $\begin{array}{c}\text { Negative } \\
\text { precision (SC6) }\end{array}$ & Precision (-) & $\begin{array}{l}\qquad \text { Precision }(-)=\frac{\mathrm{TN}}{\mathrm{TN}+\mathrm{FN}} * 100 . \\
\text { Where: } \\
\text { TN: True negative classifications } \\
\text { FN: False negative classifications }\end{array}$ \\
\hline
\end{tabular}




\begin{tabular}{|c|c|c|}
\hline $\begin{array}{c}\text { Ease of } \\
\text { interpretation } \\
\text { (SC7) }\end{array}$ & Classifier interpretation & If the classifier is easy to interpret by a clinician (2), otherwise (1) \\
\hline Box type (SC8) & Box type & If it is a black-box classifier (1), white-box classifier (2) \\
\hline Scalability (C3) & Cost category & If the cost of the learning process is over US\$1000 (1), otherwise (2) \\
\hline $\begin{array}{l}\text { Handling of } \\
\text { missing data } \\
\text { (SC9) }\end{array}$ & Handling of missing data & If the classifier is able to handle missing data (2), otherwise (1) \\
\hline $\begin{array}{c}\text { Handling of } \\
\text { continuous and } \\
\text { discrete data } \\
(\text { SC10) } \\
\end{array}$ & $\begin{array}{l}\text { Handling of continuous and } \\
\text { discrete data }\end{array}$ & If the classifier is able to handle continuous and discrete data (2), otherwise (1) \\
\hline Adaption (SC11) & Online learning capability & If the classifier is an online learning algorithm (2), otherwise (1) \\
\hline $\begin{array}{c}\text { Ease of data- } \\
\text { collection (SC12) }\end{array}$ & $\begin{array}{l}\text { Self-administered data- } \\
\text { collection }\end{array}$ & $\begin{array}{l}\text { If the feature set of the classifier is based on a self-administered screening } \\
\text { questionnaire (2), otherwise (1) }\end{array}$ \\
\hline $\begin{array}{l}\text { Overtraining } \\
\text { (SC13) }\end{array}$ & Overtraining & If the classifier does not present overtraining problems (1), otherwise (2) \\
\hline $\begin{array}{l}\text { Number of inputs } \\
\text { (SC14) }\end{array}$ & Number of inputs & $\begin{array}{l}\text { Number of simple questions that are necessary to build the feature set of the } \\
\text { classifier }\end{array}$ \\
\hline $\begin{array}{c}\text { Access to } \\
\text { validated data } \\
\text { (SC15) } \\
\end{array}$ & Algorithm validation & If the classifier has access to validated data (2), otherwise (1) \\
\hline $\begin{array}{c}\text { Statistical } \\
\text { modelling (SC16) }\end{array}$ & Type of classifier & classifier is statistical (2), otherwise (1) \\
\hline
\end{tabular}

Table 9. Initial decision matrix $X$ for selecting the most suitable classifier for supporting technology adoption in people with dementia.

\begin{tabular}{|c|c|c|c|c|c|c|c|c|c|c|c|c|c|c|c|c|c|}
\hline & SC1 & $\mathrm{SC} 2$ & $\mathrm{SC} 3$ & SC4 & SC5 & SC6 & SC7 & $\mathrm{SC} 8$ & $\mathrm{C} 3$ & SC9 & $\mathrm{SC} 10$ & SC11 & $\mathrm{SC} 12$ & $\mathrm{SC} 13$ & SC14 & SC15 & $\mathrm{SC} 16$ \\
\hline NN & 85 & 20 & 66,4 & 58,43 & 71,71 & 61,09 & 1 & 1 & 2 & 2 & 1 & 2 & 2 & 2 & 2 & 2 & 1 \\
\hline DT & 85 & 0,85 & 50,46 & 63,75 & 63,75 & 42,5 & 1 & 2 & 2 & 2 & 2 & 2 & 2 & 2 & 1 & 2 & 1 \\
\hline SVM & 82,5 & 1,3 & 47,81 & 21,25 & 23,9 & 55,78 & 1 & 1 & 1 & 1 & 2 & 2 & 2 & 1 & 1 & 2 & 2 \\
\hline NB & 34,9 & 1,23 & 23,9 & 58,43 & 50,46 & 15,93 & 2 & 2 & 1 & 2 & 2 & 2 & 2 & 1 & 2 & 2 & 2 \\
\hline$A B$ & 87,5 & 117,25 & 18,59 & 23,9 & 21,25 & 15,93 & 1 & 1 & 1 & 2 & 2 & 2 & 1 & 1 & 2 & 2 & 2 \\
\hline CART & 82,5 & 467,25 & 37,18 & 13,28 & 13,28 & 50,46 & 2 & 2 & 1 & 2 & 2 & 2 & 2 & 1 & 2 & 2 & 2 \\
\hline KNN & 82,5 & 1,06 & 21,25 & 26,56 & 23,9 & 26,56 & 2 & 2 & 2 & 2 & 2 & 2 & 1 & 2 & 1 & 2 & 2 \\
\hline $\mathrm{A}+$ & 85 & 1,3 & 66,4 & 63,75 & 71,71 & 61,09 & 2 & 2 & 2 & 2 & 2 & 2 & 2 & 1 & 2 & 2 & 2 \\
\hline A- & 34,9 & 467,25 & 18,59 & 13,28 & 13,28 & 15,93 & 1 & 1 & 1 & 1 & 1 & 1 & 1 & 2 & 1 & 1 & 1 \\
\hline$W$ & 0,042 & 0,015 & 0,026 & 0,033 & 0,032 & 0,031 & 0,204 & 0,037 & 0,255 & 0,145 & 0,053 & 0,030 & 0,020 & 0,022 & 0,013 & 0,030 & 0,014 \\
\hline Norm & 209,15 & 482,16 & 109,51 & 113,12 & 116,29 & 111,39 & 4,00 & 4,36 & 4,00 & 5,00 & 5,00 & 5,29 & 4,69 & 4,00 & 4,36 & 5,29 & 4,69 \\
\hline
\end{tabular}

Table 10. Normalized TOPSIS decision matrix $S$ for selecting the most suitable classifier for supporting technology adoption in people with dementia.

\begin{tabular}{|c|c|c|c|c|c|c|c|c|c|c|c|c|c|c|c|c|c|}
\hline & SC1 & $\mathrm{SC} 2$ & $\mathrm{SC} 3$ & SC4 & SC5 & SC6 & SC7 & SC8 & C3 & SC9 & SC10 & SC11 & $\mathrm{SC} 12$ & $\mathrm{SC} 13$ & SC14 & SC15 & SC16 \\
\hline NN & 0 & 0,041 & 1 & 1 & 1 & 0,548 & 0,250 & 0,229 & 0,500 & 0,400 & 0 & 0 & 0,426 & 0,500 & 0,459 & 0 & 0,213 \\
\hline DT & 0 & 0,002 & 0 & 1 & 1 & 0,382 & 0,250 & 0,459 & 0,500 & 0,400 & 0 & 0 & 0,426 & 0,500 & 0,229 & 0 & 0,213 \\
\hline SVM & 0 & 0,003 & 0 & 0 & 0 & 0,501 & 0,250 & 0,229 & 0,250 & 0,200 & 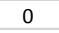 & O & 0,426 & 0,250 & 0,229 & 0 & 0,426 \\
\hline NB & 0 & 0,003 & 0 & 1 & 0 & 0,143 & 0,500 & 0,459 & 0,250 & 0,400 & 0 & 0 & 0,426 & 0,250 & 0,459 & 0 & 0,426 \\
\hline$A B$ & 0 & 0,243 & 0 & 0 & 0 & 0,143 & 0,250 & 0,229 & 0,250 & 0,400 & 0 & 0 & 0,213 & 0,250 & 0,459 & 0 & 0,426 \\
\hline CART & 0 & 0,969 & 0 & 0 & 0 & 0,453 & 0,500 & 0,459 & 0,250 & 0,400 & 0 & 0 & 0,426 & 0,250 & 0,459 & 0 & 0,426 \\
\hline KNN & 0 & 0,002 & 0 & 0 & 0 & 0,238 & 0,500 & 0,459 & 0,500 & 0,400 & 0 & 0 & 0,213 & 0,500 & 0,229 & 0 & 0,426 \\
\hline $\mathrm{A}+$ & 0 & 0,003 & 1 & 1 & 1 & 0,548 & 0,500 & 0,459 & 0,500 & 0,400 & 0,400 & 0 & 0,426 & 0,250 & 0,459 & 0 & 0,426 \\
\hline A- & 0 & 0 & 0 & 0 & 0,114 & 0,143 & 0 & 0,229 & 0,250 & 0,200 & 0 & 0 & 0 & 0,500 & 0,229 & 0 & 0,213 \\
\hline W & 0,044 & 0,014 & 0,023 & 0,030 & 0,030 & 0,028 & 0,185 & 0,047 & 0,264 & 0,155 & 0,058 & 0,031 & 0,019 & 0,023 & 0,012 & 0,026 & 0,011 \\
\hline
\end{tabular}

Table 11. Weighted normalized decision matrix $V$ for selecting the most suitable classifier for supporting technology adoption in people with dementia. 
Table 12. Euclidean distance to the positive extreme performance

\begin{tabular}{|c|c|c|c|c|c|c|c|c|c|c|c|c|c|c|c|c|c|c|}
\hline & SC1 & $\mathrm{SC2}$ & $\mathrm{SC} 3$ & SC4 & SC5 & $\mathrm{SC} 6$ & SC7 & $\mathrm{SC} 8$ & $\mathrm{C} 3$ & SC9 & $\mathrm{SC} 10$ & SC11 & $\mathrm{SC} 12$ & $\mathrm{SC} 13$ & SC14 & SC15 & SC16 & $s_{i}^{+}$ \\
\hline NN & 0,00000 & 0,00000 & 0,00000 & 0,00000 & 0,00000 & 0,00000 & 0,00214 & 0,00012 & 0,00000 & 0,00000 & 0,00013 & 0,00000 & 0,00000 & 0,00003 & 0,00000 & 0,00000 & 0,00001 & 0,04930247 \\
\hline DT & 0,00000 & 0,00000 & 0,00001 & 0,00000 & 0,00000 & 0,00002 & 0,00214 & 0,00000 & 0,00000 & 0,00000 & 0,00000 & 0,00000 & 0,00000 & 0,00003 & 0,00001 & 0,00000 & 0,00001 & 0,04714302 \\
\hline SVM & 0,00000 & 0,00000 & 0,00002 & 0,00013 & 0,00015 & 0,00000 & 0,00214 & 0,00012 & 0,00436 & 0,00096 & 0,00000 & 0,00000 & 0,00000 & 0,00000 & 0,00001 & 0,00000 & 0,00000 & 0,08874892 \\
\hline NB & 0,00011 & 0,00000 & 0,00008 & 0,00000 & 0,00003 & 0,00013 & 0,00000 & 0,00000 & 0,00436 & 0,00000 & 0,00000 & 0,00000 & 0,00000 & 0,00000 & 0,00000 & 0,00000 & 00000 & 0,06861244 \\
\hline$A B$ & 0,00000 & 0,00001 & 0,00010 & 0,00011 & 0,00017 & 0,00013 & 0,00214 & 0,00012 & 0,00436 & 0,00000 & 00000 & 0,00000 & 0,00002 & 0,00000 & 0,00000 & 0,00000 & 00000 & 08 \\
\hline CART & 0,00000 & 0,00018 & 0,00004 & 0,00018 & 0,00023 & 0,00001 & 0,00000 & 0,00000 & 0,00436 & 0,00000 & 0,00000 & 0,00000 & 0,00000 & 0,00000 & 0,00000 & 0,00000 &, 00000 & 0,07064341 \\
\hline KNN & 0,00000 & 0,00000 & 0,00009 & 0,00010 & 0,00015 & 0,00008 & 0,00000 & 0,00000 & 0,00000 & 0,00000 & 0,00000 & 0,00000 & 0,00002 & 0,00003 & 0,00001 & 0,00000 & 0,00000 & 0,02172528 \\
\hline
\end{tabular}

Table 13. Euclidean distance to the negative extreme performance

\begin{tabular}{|c|c|c|c|c|c|c|c|c|c|c|c|c|c|c|c|c|c|c|}
\hline & SC1 & $\mathrm{SC2}$ & $\mathrm{SC} 3$ & SC4 & SC5 & SC6 & SC7 & $\mathrm{SC} 8$ & SC9 & $\mathrm{SC} 10$ & SC11 & $\mathrm{SC} 12$ & $\mathrm{SC} 13$ & SC14 & $\mathrm{SC} 15$ & SC16 & SC17 & s.- \\
\hline $\mathrm{NN}$ & 0,0001 & 0,0000 & 0,0001 & 0,0001 & 0,0002 & 0,0001 & 0,0000 & 0,0000 & 0044 & 0,0010 & 0,0000 & 0,0000 & 0,0000 & 0,0000 & 0,0000 & 0,0000 & 0,0000 & 0,07817388 \\
\hline DT & 0,0001 & 0,0000 & 0,0000 & 0,0002 & 0,0002 & 0,0000 & 0,0000 & 0,0001 & 0,0044 & 0,0010 & 0,0001 & 0,0000 & 0,0000 & 0,0000 & 0,0000 & 0,0000 & 0,0000 & 0,07868843 \\
\hline SVM & 0,0001 & 0,0000 & 0,0000 & 0,0000 & 0,0000 & 0,0001 & 0,0000 & 0,0000 & 0,0000 & 0,0000 & 0,0001 & 0,0000 & 0,0000 & 0,0000 & 0,0000 & 0,0000 & 0,0000 & 0,02232146 \\
\hline NB & 0,0000 & 0,0000 & 0,0000 & 0,0001 & 0,0001 & 0,0000 & 0,0021 & 0,0001 & 0,0000 & 0,0010 & 0,0001 & 0,0000 & 0,0000 & 0,0000 & 0,0000 & 0,0000 & 0,0000 & 0,06089759 \\
\hline$A B$ & 0,0001 & 0,0000 & 0,0000 & 0,0000 & 0,0000 & 0,0000 & 0,0000 & 0,0000 & 0,0000 & 0,0010 & 0,0001 & 0,0000 & 0,0000 & 0,0000 & 0,0000 & 0,0000 & 0,0000 & 0,0366929 \\
\hline CART & 0,0001 & 0,0002 & 0,0000 & 0,0000 & 0,0000 & 0,0001 & 0,0021 & 0,0001 & 0,0000 & 0,0010 & 0,0001 & 0,0000 & 0,0000 & 0,0000 & 0,0000 & 0,0000 & 0,0000 & 0,06202278 \\
\hline KNN & 0,0001 & 0,0000 & 0,0000 & 0,0000 & 0,0000 & 0,0000 & 0,0021 & 0,0001 & 0,0044 & 0,0010 & 0,0001 & 0,0000 & 0,0000 & 0,0000 & 0,0000 & 0,0000 & 0,0000 & 0,08887345 \\
\hline
\end{tabular}

